\title{
Quorum sensing can be repurposed to promote information transfer between bacteria in the mammalian gut
}

\section{Citation}

Kim, Suhyun. 2019. Quorum sensing can be repurposed to promote information transfer between bacteria in the mammalian gut. Doctoral dissertation, Harvard University, Graduate School of Arts \& Sciences.

\section{Permanent link}

http://nrs.harvard.edu/urn-3:HUL.InstRepos:42029725

\section{Terms of Use}

This article was downloaded from Harvard University's DASH repository, and is made available under the terms and conditions applicable to Other Posted Material, as set forth at http:// nrs.harvard.edu/urn-3:HUL.InstRepos:dash.current.terms-of-use\#LAA

\section{Share Your Story}

The Harvard community has made this article openly available. Please share how this access benefits you. Submit a story. 
Quorum sensing can be repurposed to promote information transfer between bacteria in the mammalian gut

A dissertation presented

by

Suhyun Kim

to

The Department of Molecular and Cellular Biology

in partial fulfillment of the requirements

for the degree of

Doctor of Philosophy

in the subject of

Biology, Molecular and Cellular

Harvard University

Cambridge, Massachusetts

October 2018 


\section{(C) 2019 Suhyun Kim}

All rights reserved.

Part of this dissertation is reprinted with permission ACS Synth. Biol. 2018, 7, 9, 2270-2281. Copyright 2018 American Chemical Society. 


\title{
Quorum sensing can be repurposed to promote information transfer between bacteria in the mammalian gut
}

\begin{abstract}
The gut microbiome is intricately involved with establishing and maintaining the health of the host. Engineering of gut microbes aims to add new functions and expand the scope of control over the gut microbiome. To create systems that can perform increasingly complex tasks in the gut, it is necessary to first harness the ability of the bacteria to communicate in the gut environment. Interestingly, acyl-homoserine lactone (acyl-HSL)-mediated Gram-negative bacterial quorum sensing, a widely-used mode of inter-cellular signaling system in nature, has not been identified in normal healthy mammalian gut. It remains unknown whether the gut bacteria that do not natively use quorum sensing can be engineered to successfully signal to other bacteria using acyl-HSLs in the gut despite the inherent challenges imposed by this complex environment. Here, I repurposed quorum sensing to create an information transfer system between native gut Escherichia coli and attenuated Salmonella enterica serovar Typhimurium. Specifically, I functionalized one species with inducible signal production and the other with signal detection and recording using genomically integrated circuits. The information transfer system demonstrated successful intra-and inter-species signaling in the murine gut. This study provides a basis for further understanding of inter-bacterial interactions in an otherwise hard-tostudy environment as well as a basis for further investigation of the potential of acyl-HSLs as inter-cellular signaling molecules of engineered gut consortia.
\end{abstract}




\section{Table of Contents}

Chapter 1. Introduction (p.1)

Chapter 2. Designing, building, and characterizing the information transfer system in vitro (p. 11)

Chapter 3. Characterizing the information transfer system in the mammalian gut (p. 29)

Chapter 4. Conclusion (p. 45) 


\section{Acknowledgments}

I would like to thank my advisor Dr. Pamela Silver for opportunities to study engineering the gut microbiome and for advices and discussions along the way. I would also like to thank the Wyss Senior Staff Scientist, Dr. Jeffrey Way, for discussions and guidance.

David Lips, during his master's thesis research internship, worked with me and we explored and learned a lot together about quorum sensing systems in general and cross talks among different systems. Dr. S. Jordan Kerns and Dr. Marika Ziesack contributed to the research by sharing their strains (The Salmonella memory element strain and the attenuated Salmonella strain, respectively). Dr. Georg Gerber and Dr. Lynn Bry at Brigham and Women’s Hospital were my collaborators for the gnotobiotic experiments discussed in this thesis. Many Silver lab members helped me grow during my time as a graduate student by sharing tips, lively scientific discussions, reagents, and feedback.

My deepest appreciation and prayers go to my loved ones.

2019 May

Suhyun Kim 
Chapter 1.

\author{
Introduction
}




\section{Studies on the gut microbiome}

The gut microbiome has crucial roles in establishing and maintaining the health of the host, including the development of the immune system, nourishment of the gut epithelial cells, production of metabolites, neuromodulation, weight changes, and protection against pathogens (Ayres et al., 2012; Clemente, et al., 2012; Dodd et al., 2017; Everard et al., 2013; Kim et al., 2017; Peterson, et al., 2009; Ridaura et al., 2013; Sampson et al., 2016; Yano et al., 2015).

Several approaches have been taken to study the gut microbiome. The metagenomics approach uses the genes encoding the $16 \mathrm{~S}$ rRNA or equivalents to identify the composition of the microbiome in a more complete and less biased way than the previous culture-based methods have allowed (Jovel et al., 2016; Zhernakova et al., 2016). The proteomics and metabolomics approach focuses on characterizing microbial products and provide information that sequencing alone would miss, such as the identities of key proteins or metabolites produced by bacteria (Xiong et al., 2015; Walker et al., 2014). Fecal transplants in research and clinical settings aim to produce system-level changes, and has demonstrated surprising before-and-after effects of the healthy native microbiota on fighting pathogens such as Clostridium difficile and reducing weight gains, anxiety, and jet-lag of the host (Bakken et al., 2011; De Palma et al., 2017; Hsiao et al., 2013; Thaiss et al., 2014). The focused perturbation approach studies the effects of pathogens, probiotics, and genetically engineered bacteria on the rest of the microbiome and the well-being of the host (Baumler and Sperandio, 2016; Thomas and Versalovic, 2010). Lastly, imaging analysis approach studies the micron-scale biogeography of the microbes in the gut and what may be learned about interactions by visualizing cells in situ (Earle et al., 2015; Mark Welch et al., 2017; Whitaker et al., 2017). Studies employing these approaches, either alone or 
in combinations, have suggested the importance of complex networks of interactions among the gut bacteria in homeostasis and dysbiosis (Baumler and Sperandio, 2016; Kamada et al., 2013).

\section{Active interventions to reshape the gut microbiome}

The gut microbiome can be reshaped through various measures, such as dietary changes, antibiotic treatments, and fecal transplants (Smillie et al., 2018; Turnbaugh et al., 2009; Zou et al., 2018). These approaches can have prominent and lasting changes, but are limited in that they result in wholesale changes with limited levels of control and definition.

Engineering of gut microbes poses an opportunity to overcome these limitations and expand the scope of control over the gut microbiome. This synthetic biology approach has shown progress in several aspects. First, engineered bacterial sensors can successfully detect their target molecules in the gut, such as orally administered anhydrotetracycline (ATC) and gut inflammatory markers, thiosulfate and tetrathionate (Daeffler, et al., 2017; Kotula et al., 2014; Riglar et al., 2017). Second, engineered bacteria with information recording systems using genetic switches can report on the state of the gut through fecal sample analysis (Kotula et al., 2014; Slauch et al., 2000; Mimee et al., 2016). Third, synthetic circuits can enable bacteria to produce beneficial molecules in the gut to improve the health of the host (Riglar and Silver, 2018

for review). Finally, suicide switches can enhance the biocontainment strategy of the engineered bacteria (Chan et al., 2015; Stirling et al., 2017). Overall, these approaches have shown advances in programing gut microbes with distinct functions for potential practical applications. 


\section{Engineering artificial communication for the gut bacteria}

Although significant progress has been made in engineering the gut bacteria, little is known about programming direct communication, which is a crucial component for building multiplexed systems and obtaining higher levels of control over engineered gut consortia. Moreover, our understanding of native bacterial communication in the gut is still at an early stage. For instance, while studies reported the presence of nutrient- or metabolite-dependent interactions and pan-bacterial interaction using the autoinducer 2 (AI-2) (Thompson et al., 2015), the Gram-negative bacterial quorum sensing, which is prevalent in nature, has not been detected in the normal healthy mammalian gut (Rakoff-Nahoum, et al., 2014; Swearingen et al., 2013).

Quorum sensing relies on the production and the detection of small molecules that can freely diffuse in and out of cells (Fuqua et al., 2001; Miller and Bassler, 2001 for review). The Gram-negative bacterial quorum sensing archetype consists of a luxI-homolog encoding the synthase of an acyl-HSL variety and a luxR-homolog encoding a transcription factor that activates the target genes when it is bound to a compatible acyl-HSL (Fig 1) (Marketon et al., 2002; Piper et al., 1993; Rosemeyer et al., 1998). In nature, the luxI/R-type quorum sensing is thought to provide a means for many species of bacteria to distinguish their population density in a species-specific manner and modulate group behaviors such as biofilm formation and virulence factor production (Engebrecht et al., 1983; Passador et al., 1993; Swift et al., 2001). 


\section{Figure 1}

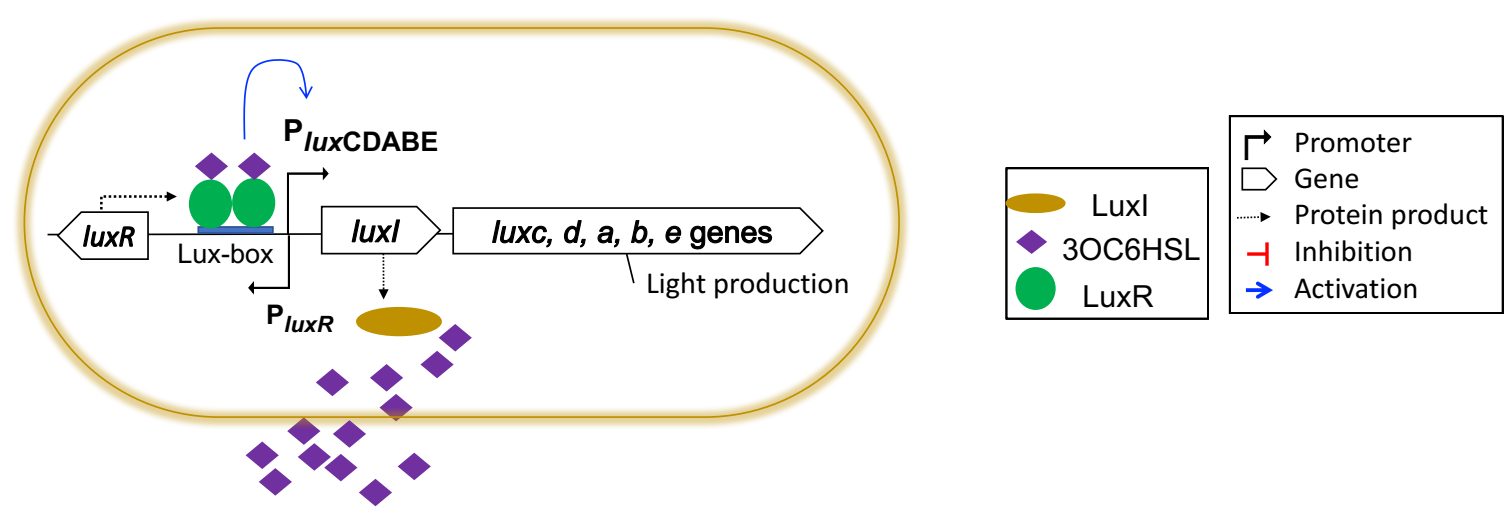

Aliivibrio fischeri, a gram-negative symbiont of the Hawaiian bobtail squid, has its native Lux operon for quorum sensing. Each bacterium constitutively produces LuxR, which requires binding to 3OC6HSL to activate the PluxCDABE promoter. At low cell densities, there is basal expression from PluxCDABE. At high cell densities, the promoter is activated and leads to a high level of expression of luxI, and the downstream genes involved in the light production.

The absence of easily detectable acyl-HSLs in the normal mammalian gut despite very high densities and diversity of microflora has raised questions on whether the mammalian gut environment is inherently prohibitive to acyl-HSL-mediated signaling due to active signal degradation (Swearingen, et al., 2013). Two cases where acyl-HSLs were detected by engineered bacteria required pathogenic gut environment, where the mice were infected with Yersinia enterocolitica or Pseudomonas aeruginosa, both of which naturally use quorum sensing through signal production and detection (Dyszel et al., 2010, Hwang et al., 2016). However, it remains unknown whether the gut bacteria that normally do not use quorum sensing can be engineered to successfully signal to other bacteria in the gut using acyl-HSL. For instance, a study using microfluidic devices that control flow rate reported that whereas $P$. aeruginosa that naturally utilizes quorum sensing was resistant to flow in its signaling ability, E. coli engineered to 
produce and detect the same signal lost its ability to successfully signal when there is flow (Emge et al., 2016).

Another important point to investigate is whether expressing the luxI/R genes as genomeintegrated single copies is sufficient to create viable inter-cellular communication in vivo. Although the luxI/R-type genes have been adopted to create novel functions in E. coli including artificial cell patterning, logic gates, synchronization, and population density regulation, they were mainly expressed in multi-copy plasmids optimal for in vitro settings only (Basu et al., 2005; Brenner et al., 2007; Hwang et al., 2016; Scott et al., 2017; Tabor et al., 2009; Tamsir et al., 2011). Studies on native quorum sensing in Agrobacterium tumefaciens and Pseudomonas aeruginosa also overexpressed traI/R and lasI $/ R$ using multi-copy plasmids to express these luxI/R homologs (Steindler and Venturi, 2007; Zhu et al., 2003). Increasing the expression levels of the luxI/R homologs increase the signal production and detection capability. For instance, a study in $E$. coli reported that increasing the copy number of luxR from a single-copy to low, medium, and high copies increased the fluorescence output from PluxI by approximately 3-, 30-, and 40-folds (Zucca et al., 2012). However, using multi-copy plasmids is not optimal in engineering bacteria for in vivo applications, since most plasmids require antibiotics for maintenance and high expression levels can cause excessive metabolic burden to the engineered strains (Borkowski et al., 2016; Sleight and Sauro, 2013; Wu et al., 2016). Therefore, it is important to investigate whether expressing both the luxI and the luxR genes as genomeintegrated single copies in non-native chasses still create viable inter-cellular communication in vitro and in vivo. 


\section{Genetic switches to record information in the gut}

Engineered bacteria that can sense and report on the presence of molecules or events of interest can be valuable tools in probing the gut. These bacteria use genetic elements to link sensing to recording, so that the events that occurred transiently or early during the passage through the gut are not lost by the time the bacteria exit the host. These genetic elements include recombineering-based reporter systems built for E. coli, $S$. Typhimurium, and Bacteroides thetaiotaomicron, as well as the genetic switch-based "memory element" for E. coli developed by the Silver lab (Kotula et al., 2014; Slauch et al., 2000; Mimee et al., 2016). For the present study, I adopted this previously published memory element as the information recording system. The memory element is a bi-stable genetic switch for $E$. coli that incorporates bacteriophage lambda sequences (Kotula et al., 2014). In nature, the bacteriophage lambda of E. coli uses a bistable genetic element regulated by the two competing proteins $\mathrm{CI}$ and Cro to switch between the lytic and the lysogenic states (Fig 2). (Ptashne, 1987 and Ptashne and Gann, 2002 for review on the genetic switch of the bacteriophage lambda). The memory element contains parts of the native lambda genes spanning from the left operators $\left(\mathrm{O}_{\mathrm{L}}\right)$ to the cro gene. The default "OFF" state is dominated by $\mathrm{CI}$ that activate the transcription of the $\mathrm{P}_{\mathrm{RM}}$ promoter through cooperative binding on $\mathrm{O}_{\mathrm{R}} 1, \mathrm{O}_{\mathrm{R}} 2, \mathrm{O}_{\mathrm{L}} 1$, and $\mathrm{O}_{\mathrm{L}} 2$ to produce more $\mathrm{CI}$ through positive feedback, while simultaneously blocking the $\mathrm{P}_{\mathrm{R}}$ promoter to repress the transcription of $c r o$. The induciblenegative version of the $c I$ gene $\left(c I^{i n d-}\right)$ was used to prevent response to internal or external perturbations and stress such as the UV light from inducing the genetic switch (Gimble and Sauer, 1986; Gimble and Sauer, 1989). The memory element responds to an engineered genetic element termed the "trigger element," with an inducible promoter of interest regulating another copy of cro. Once the inducible promoter of the Trigger element is activated and enough Cro is 
produced, Cro binds to $\mathrm{O}_{\mathrm{R}} 3$ and prevents further transcription of $c l^{\text {ind- }}$ from $\mathrm{P}_{\mathrm{RM}}$. With a few cell divisions, the concentration of $\mathrm{CI}^{\text {ind- }}$ quickly declines and the transcription from $\mathrm{P}_{\mathrm{R}}$ is derepressed. The partial lambda genes of the memory element are inserted between the $m h p R$ locus and the lacZ locus of the E. coli genome in such a way that after the cro gene, lac $Z$ follows immediately without another RBS. Functional test had demonstrated that this design successfully allowed easy chromatic detection of the ON state by eye, using plates containing Xgal.

Presumably, a nearby sequence within the cro gene functions as an RBS for lac $Z$ so that the two genes are transcribed as a bi-cistronic structure. Since the memory element contains the two sets of three native operators consisting $\mathrm{O}_{\mathrm{L}}$ an $\mathrm{O}_{\mathrm{R}}$, there is also self-repression of the cro gene from the $P_{R}$ promoter at a very high level of Cro, which then occupies not only $O_{R} 3$, but also $O_{R} 1$ an $\mathrm{O}_{\mathrm{R}} 2$.

\section{Figure 2}
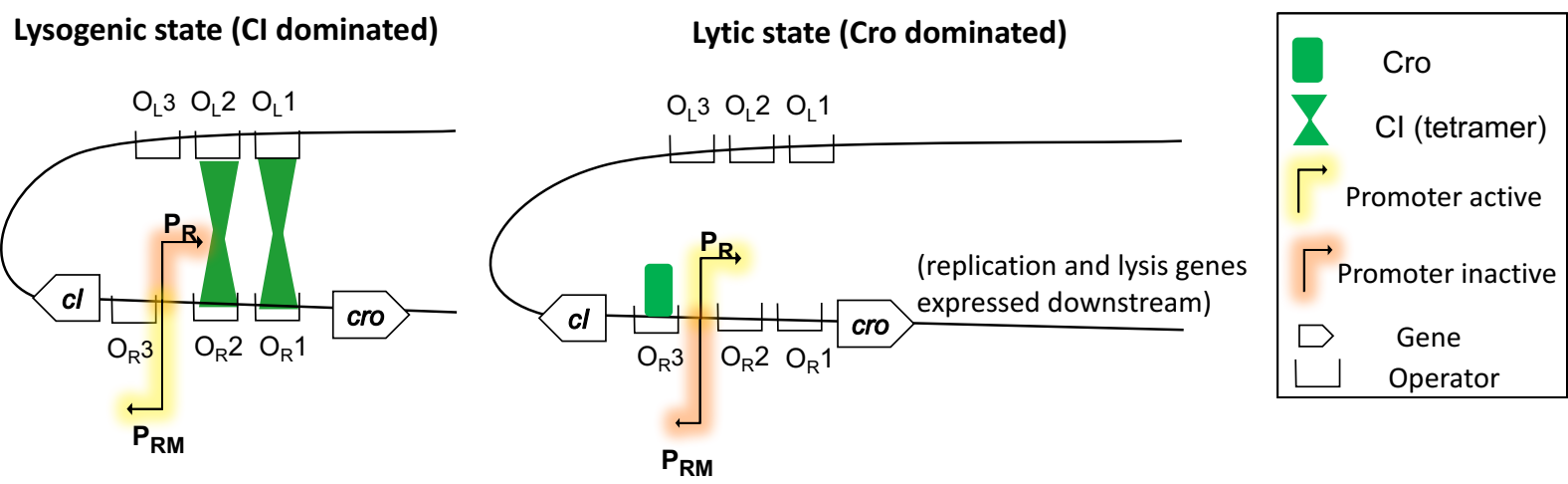

The tug-of war between $\mathrm{Cro}$ and $\mathrm{CI}$ in the bacteriophage lambda genetic switch decides lysogenic vs lytic states. In the CI-dominated state (left), $\mathrm{P}_{\mathrm{RM}}$ is activated by the CI octamer that creates a loop, linking the $\mathrm{O}_{R}$ and $\mathrm{O}_{L}$ operators to increase stability. $\mathrm{P}_{R}$ is blocked by CI. Genes downstream of $c I$ are involved in establishing a lysogenic state. In the Cro-dominated state (right), Cro binds to $\mathrm{O}_{\mathrm{R}} 3$ and blocks $\mathrm{P}_{\mathrm{RM}}$. In the absence of $\mathrm{CI}, \mathrm{P}_{\mathrm{R}}$ is constitutively active. This leads to continued expression of cro, as well as genes involved in viral replication and bacterial lysis. 


\section{Animal studies to understand the gut microbiome}

It is difficult in many cases to conduct controlled studies on the microbiome directly on human subjects due to ethical and practical concerns, especially if the control or the experimental arm may lead to potentially negative consequences. Currently, mice are used as the main model organisms to study the mammalian microbiome, especially if studies require active perturbations. The laboratory mice for studying the microbiome can be grouped into conventional mice and gnotobiotic mice. The conventional mice have uncontrolled background gut microflora, while the gnotobiotic mice are grown and maintained in germ-free conditions until they are populated with defined microflora according to the study designs. The mice are then continued to be maintained in special isolation systems to prevent unintended introduction of microbes. Both categories have strengths and weaknesses. Since the conventional mice are colonized with native microflora, they provide more realistic background when testing the effects of perturbations, such as introduction of pathogens or engineered bacteria. However, the uncontrolled and undefined background flora creates rooms for variation in different mice. The background flora can be significantly different from experiment to experiment, depending on vendors, mouse facilities, husbandry, and other aspects that are difficult to unify or are often neglected (Franklin et al., 2017). Characterizing the background flora before and during the experiment can be complex and time-consuming on its own, making it difficult to include it in every study. The gnotobiotic mice have clear advantages over the conventional mice with this regards, as they are populated with defined flora of interest and are free of variability that comes from the undefined and uncontrolled background native flora. Furthermore, the gnotobiotic mice can be colonized with the microbiota obtained from human subjects and thus provide another means to study the human microbiome in vivo. However, gnotobiotic mice are worse at representing normal, healthy 
physiology of mice (Luczynski et al., 2016 for review). While these mice are born and maintained in germ-free settings, they develop physiological and structural abnormalities that compromise important functions involved in the immune system, metabolism, nervous system, and many others. The gastrointestinal tract of the germ-free mice also shows abnormal cell sizes, organ proportions, cellular turnover, and metabolic capacity (Luczynski et al., 2016).

\section{Summary of work}

I engineered an information transfer system to probe whether the Gram-negative bacterial quorum sensing system can be repurposed into a functional, artificially-established language for the mammalian gut. Specifically, the system entailed inducible signal production in one species and signal detection and recording in the other species using genomically integrated single-copy circuits in a native gut $E$. coli and attenuated $S$. Typhimurium (Fig 3a). The system was quantitatively analyzed in vitro to characterize system performance under a defined and controlled environment. The system was then tested in both conventional mice and gnotobiotic mice to test viability and robustness. Overall, the information transfer system demonstrated the potential of acyl-HSLs as the signaling molecules to create artificial communication among the engineered gut consortia. 


\section{Chapter 2.}

\section{Designing, building, and characterizing the information transfer system in vitro}

\section{Chapter summary}

The information transfer system aims to establish and report on successful inter-cellular communication in the gut using acyl-HSL as the signal. Given this goal, the system was built with design principles suitable for in vivo applications, such as integrating all circuits as genomeintegrated single copies. The system entail the "signaler" cell that produces 3OC6HSL when induced by ATC and the "responder" cell that reports on the detection of 3OC6HSL. Both the signaler and the responder were engineered using native murine gut $E$. coli and attenuated $S$. Typhimurium as the chasses. Time course dosage analysis showed exposure time- and signal dosage-dependent increase in response of both responders, and that the E. coli responder is a more sensitive and rapid biosensor than the $S$. Typhimurium responder. Quantitative analysis showed that the signalers are efficient producers of the signal in an in vitro culture condition. Finally, I built a simple model to further describe and predict how the signaler shapes its microenvironment. 


\section{$\underline{\text { Results }}$}

\section{Engineering the information transfer system in $E$. coli and $S$. Typhimurium}

I designed genetic elements for inducible acyl-HSL-production in the signaler strain and for the signal detection and recording in the responder strain. The signaler was engineered to produce an acyl-HSL variety, $N$-(3-oxo-hexanoyl)-L-HSL (3OC6HSL), in response to an orally deliverable tetracycline-analog, anhydrotetracycline (ATC), using what I termed the sense-signal element. In the absence of ATC, the sense-signal element constitutively produces Tet repressors (TetR) that inhibit the PtetA promoter from transcribing luxI, which encodes the synthase of 3OC6HSL. ATC de-represses the inhibitory effect and allows the production of 3OC6HSL (Fig 3b). The responder was engineered to detect and record the reception of 3OC6HSL through the Lux-trigger element and the memory element. The Lux-trigger element leads to the expression of cro when the responder detects 3OC6HSL (Fig 3b). This element constitutively produces the LuxR protein, which binds to 3OC6HSL and interacts with the Lux-box element of the PluxI promoter to activate the transcription of cro (Fig 3b). The Cro produced from the Lux-trigger element then acts on the previously described memory element (Kotula et al, 2014) to switch to a stable $\mathrm{ON}$ state. Once the memory element is switched $\mathrm{ON}$, two genes, lacZ and the second copy of cro, are expressed through the memory element (Fig 3b). The expression of lacZ enables the use of blue-white colony screening to identify the ON state responder cells. The expression of the second copy of cro through the memory element forms a positive feedback loop to maintain the ON state even when the first copy of cro in the Lux-trigger element is no longer expressed.

The signaler and the responder were first constructed in the commensal murine gut $E$. coli strain, NGF, which has been shown to stably colonize the mouse gut (Kotula et al., 2014). The signaler was engineered by integrating a copy of the sense-signal element into the NGF 
genome. Using the NGF strain already containing the memory element (Kotula et al., 2014), I constructed the responder by further integrating the Lux-trigger element via $\mathrm{Tn} 7$ integration system.

Next, I constructed the $S$. Typhimurium version of the information transfer system. I used an attenuated strain background in the lab without the SPI-1 and the SPI-2 pathogenicity islands, which are involved in the Type-III secretion system for invasion into the host cells. I confirmed by colony PCR and sequencing that most regions of SPI- 1 and 2 were absent in this strain (See Methods for the exact locations). The resulting strain did not cause outwardly visible adverse effects in mice, such as ruffled fur, lethargy, and weight loss, even when it colonized the gut at high densities ( $>10^{9} \mathrm{CFU} / \mathrm{g}$ of feces, Fig $\left.9 \mathrm{a}\right)$. The $S$. Typhimurium signaler and the responder were built with the same design principles as those used in engineering the $E$. coli equivalents (Fig 3b). The $S$. Typhimurium signaler was created by integrating the $S$. Typhimurium codonoptimized sense-signal element into the yafB-yafC intergenic locus, where incorporating a large synthetic DNA does not lead to an obvious growth defect. The $S$. Typhimurium responder was created by integrating the $S$. Typhimurium codon-optimized Lux-trigger element and the memory element, which was adopted from the $E$. coli responder. 


\section{Figure 3}

$\mathbf{a}$

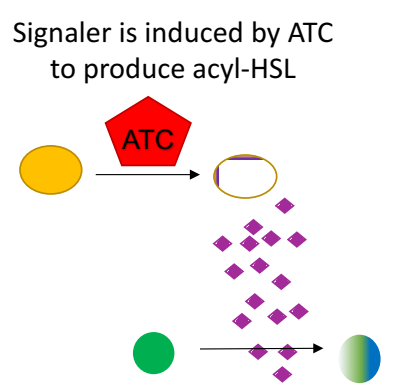

Responder detects acyl-HSL
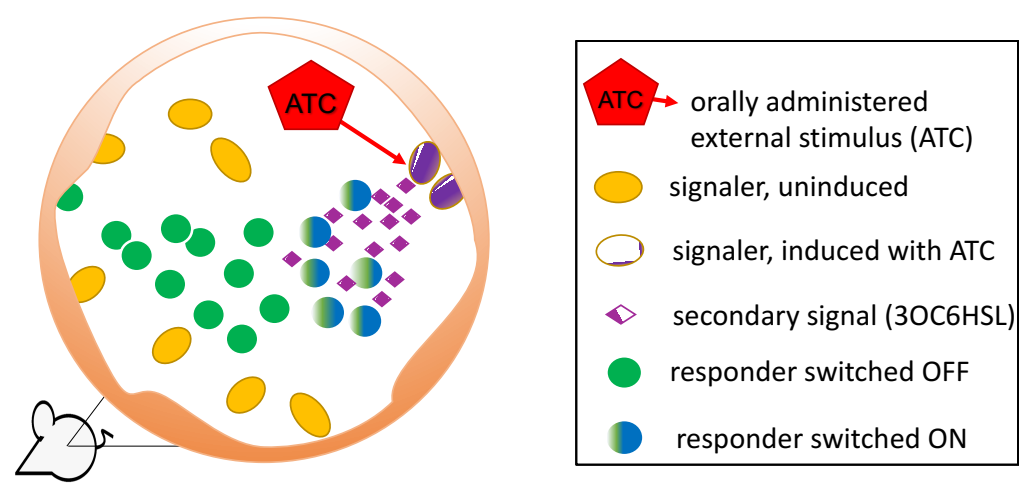

b

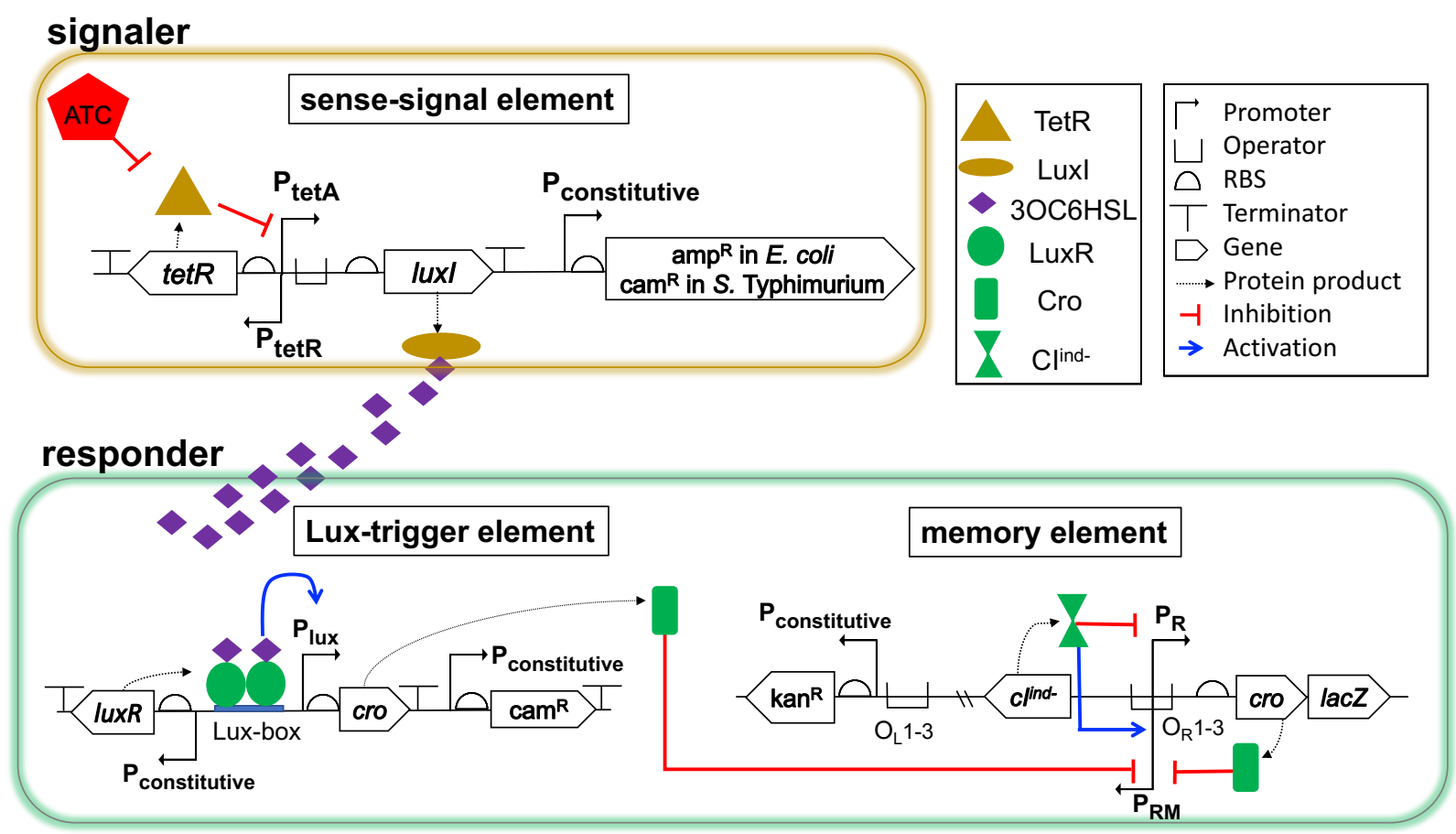

The information transfer system as a control element for the synthetic gut microbiome. a The abstraction of the information transfer system to establish and detect artificial communication in the gut. The signaler responds directly to the primary signal, ATC, and propagates the information to the responder using the secondary signal, 3OC6HSL. The responder switches $\mathrm{ON}$ in response to 3OC6HSL. b The diagram of the genome-integrated single copy circuits to make the signaler and the responder sense, relay, and record information as a pair. The signaler uses the sense-signal element to express luxI in the presence of ATC. The responder uses the Lux-trigger to express cro in the presence of 3OC6HSL. Once enough Cro is accumulated, the memory element switches $\mathrm{ON}$ to express $l a c Z$ as well as the second copy of cro to maintain the $\mathrm{ON}$ state. 


\section{The $E$. coli and the $S$. Typhimurium responders switch ON in response to 3OC6HSL}

I first characterized the responder as the biosensor of 3OC6HSL and subsequently used it to characterize the signaler as the producer of 3OC6HSL. The E. coli responder demonstrated a time-dependent dosage response to 3OC6HSL with high sensitivity and a good dynamic range. I exposed the $E$. coli responder to different concentrations of the 30C6HSL standards for different lengths of time. The percentage of switched ON responders was calculated by plating the samples on agar indicator plates containing Xgal and counting the percentage of blue colonies (Fig 4a). The E. coli responder showed high sensitivity to the signal, with more than $50 \%$ of the cells switched ON with $3 \mathrm{nM}$ at $\mathrm{t}=1 \mathrm{~h}$. By $\mathrm{t}=2 \mathrm{~h}$, more than $98 \%$ of the responder cells switched ON, even with the lowest concentration tested (3nM) (Fig 4b). As expected, longer exposure times led to higher percentages of switching ON.

The $S$. Typhimurium responder also demonstrated sensing of 3OC6HSL, with more cells switching ON at higher concentrations of 3OC6HSL and with longer exposure times (Fig 4a, 4c). In comparison to the E. coli responder, however, it was slower and less sensitive; after exposure to the highest concentration of 3OC6HSL tested $(100 \mathrm{uM})$ for $4 \mathrm{~h}$, the $S$. Typhimurium responder switched ON to about $25 \%$ (Fig 4c).

\section{The $E$. coli and the $S$. Typhimurium signalers sense ATC and efficiently produce}

\section{OC6HSL}

Using the $E$. coli responder as a biosensor of $30 \mathrm{OC} 6 \mathrm{HSL}$, I quantified the production rates of $30 \mathrm{OC} 6 \mathrm{HSL}$ by the $E$. coli and the $S$. Typhimurium signalers. The $E$. coli signaler demonstrated production of 3OC6HSL with high efficiency and capacity when induced with ATC. The signaler was induced with ATC $(100 \mathrm{ng} / \mathrm{mL})$ for $1 \mathrm{~h}$. The signaler growth curve was obtained 
based on the colony forming units per $\mathrm{mL}(\mathrm{CFU} / \mathrm{mL})$ of the signaler at $\mathrm{t}=0,30$, and $60 \mathrm{~min}$ (details in Methods). At the endpoint, the filtered and cell-free signaler supernatants were serially diluted into fresh media, into which the responder was inoculated to detect 3OC6HSL (Fig 4d). The concentrations of 3OC6HSL in the supernatants were calculated by comparing the percentage switched $\mathrm{ON}$ of the responders when exposed to the diluted signaler supernatants versus the 3OC6HSL standards (Methods). Furthermore, using the estimated contributing signaler cell numbers over time, the production rate of 3OC6HSL during the exponential growth phase was obtained as the number of molecules produced per signaler cell per min (Table 1 and Methods). The negative control using the uninduced signaler supernatant resulted in no switching ON of the responder as expected.

The $S$. Typhimurium signaler also successfully produced 3OC6HSL when induced with ATC, with the efficiency and the capacity lower than those of the E. coli signaler. Using the same assay with minor modifications (Fig 4a), I found that compared to the E. coli signaler, the S. Typhimurium signaler produced approximately 6-fold less 3OC6HSL per cell per min in response to ATC (Table 1). This production rate would still be high enough to lead to successful information transfer in the mouse gut, based on the observed density in the mouse gut for our attenuated strain of $S$. Typhimurium $\left(>10^{9} \mathrm{CFU} / \mathrm{g}\right)$. For instance, the production rate of $\sim 4100$ molecules per signaler per min (Table 1) means that if the local density of the signaler in a closed environment is $5 \times 10^{8} \mathrm{CFU} / \mathrm{mL}$, after 1 min the concentration of 3OC6HSL would have already reached $3 \mathrm{nM}$, which is approximately the EC50 value of the E. coli responder in our time course dosage experiment (Fig 4b, at exposure time 1h). Nevertheless, it should be noted that these rates of production were calculated for the exponential phases of growth in well-defined in vitro conditions and that the production rates in the complex environment of the gut may be different. 


\section{Figure 4}

\section{a}

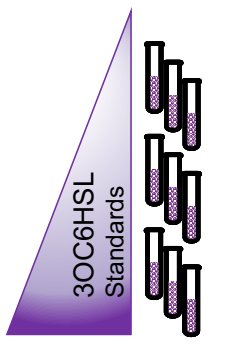

Responder in LB+30C6HSL liquid cultures

b

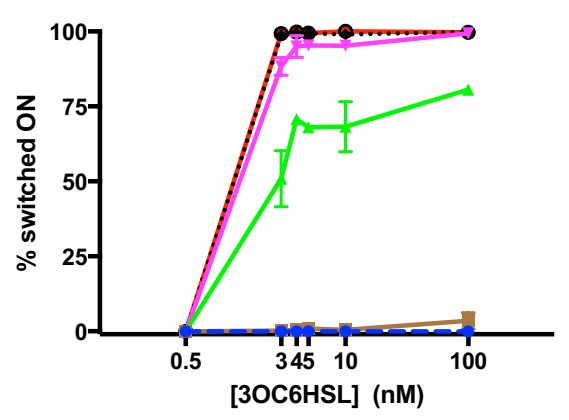

Cells in exponential phase. Time course sampling and plating.

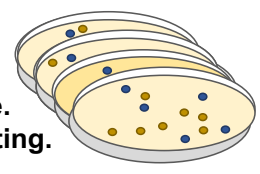

LB+strep+kan+Xgal

Count blue

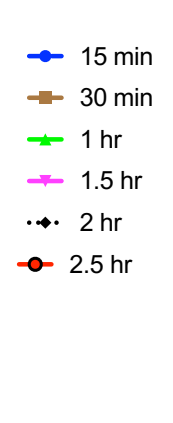

$\rightarrow 15$ min

$30 \mathrm{~min}$

$-15 \mathrm{hr}$

... $2 \mathrm{hr}$

$-2.5 \mathrm{hr}$

c

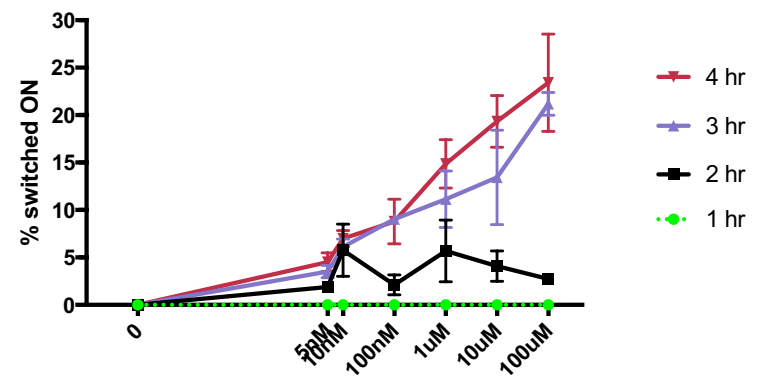

[30C6HSL]

d

Signaler produces $30 \mathrm{C} 6 \mathrm{HSL}$

Biosensor detects 30C6HSL

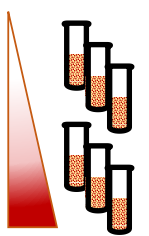

Signaler with ATC

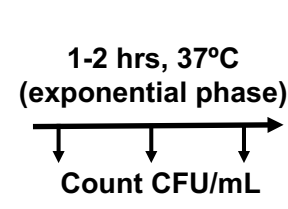

1-2 hrs, $3-^{\circ} \mathrm{C}$ exponential phase Count CFU/mL

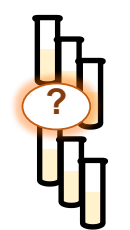

Make dilutions of filtered supernatant

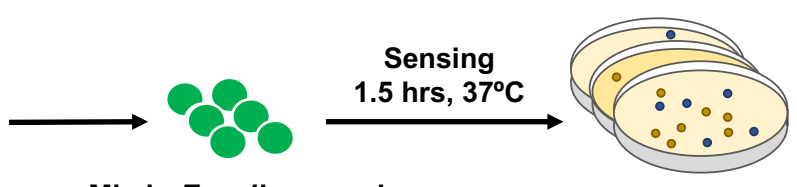

Mix-in E. coli responder
LB+strep+kan+Xgal Count \% blue of responder

Characterization of the responder and the signaler as the biosensor and the producer of 30C6HSL, respectively. a Experimental procedure to characterize the time course dosage response of the responder. The responder was sampled every $0.5 \mathrm{~h}$ from $\mathrm{t}=0$ to $2.5 \mathrm{~h}$ (E. coli) or hourly from $\mathrm{t}=0$ to $4 \mathrm{~h}$ ( $S$. Typhimurium) to count the percentage of blue colonies. b E. coli responder sensing 30C6HSL. Mean with SD; $\mathrm{n}=3$. c $S$. Typhimurium responder sensing 3OC6HSL. Mean with SD; $n=3$. d Procedure to quantify the production rates of 3OC6HSL by the signalers. The signaler was induced with ATC $(100 \mathrm{ng} / \mathrm{mL})$ for $1 \mathrm{~h}(E$. coli $)$ or $2 \mathrm{~h}(S$. Typhimurium) in LB liquid media. CFU/mL values were used to obtain the signaler growth curve. To the serially diluted, cell-free signaler supernatants, the E. coli responder was mixed in for $1.5 \mathrm{~h}$ for biosensing. Control responder cells were exposed to the 3OC6HSL standards to get the standard curve. The percentage of blue colonies was obtained by using Xgal plates. 
Table 1

The rates of production of 3OC6HSL by the $E$. coli and the $S$. typhimurium signalers.

\begin{tabular}{|c|c|c|c|}
\hline & $\begin{array}{c}\text { [3OC6HSL] in } \\
\text { supernatant }(\mathbf{n M})\end{array}$ & $\begin{array}{c}\text { Calculated } \\
\text { Area under curve } \\
\text { (CFUxmin) }\end{array}$ & $\begin{array}{c}\text { Calcuction rate } \\
\text { production } \\
\text { (molecules made } \\
\text { per cell per min) }\end{array}$ \\
\hline E. coli & $27 \pm 6.9$ & $7.5 \times 10^{8}$ & $22000 \pm 5500$ \\
\hline S. Typhimurium & $24 \pm 2.6$ & $3.5 \times 10^{9}$ & $4100 \pm 440$ \\
\hline
\end{tabular}

The concentration of 3OC6HSL in the supernatant was obtained using non-linear fitting of the standard curve and interpolating the values based on the percentage of the switched ON responders in the supernatant dilutions. The area under curve reported is for the signaler growth curve during the exposure to ATC. The production rate was obtained by dividing the total number of 3OC6HSL molecules in the supernatant by the area under growth curve. Mean \pm SD of the multiple interpolated values from the signaler supernatant dilutions. (Details in Methods).

\section{Model describes the dynamic changes of the environment shaped by the signaler}

To further our understanding of the system, I modeled how the signaler causes the dynamic changes in the concentration of 3OC6HSL in the immediate environment. The model presupposes three conditions: the environment is constantly mixing; the degradation of 3OC6HSL within the time scale of interest is negligible; and the net flux of 3OC6HSL in and out of the said environment is zero. In the case of constantly-mixing short-term in vitro cultures where these conditions are satisfied, the model is expected to provide a proper description of the system. In the case of more complex settings such as the gut, the model would serve as an approximate description of the immediate surrounding environment. The concentration of 3OC6HSL would increase in proportion to the density and the resident time (how long it has stayed in the given environment) of the signaler population (Fig 5a).

The experimentally determined 30C6HSL production rates of the E. coli and the $S$. Typhimurium signalers allowed quantitative predictions (Table 1, Fig 5b, 5d). If the signaler 
population density is at an equilibrium, the concentration of 3OC6HSL (nM) in the environment at any given time can be calculated as the product of the production rate ([HSL] (nM) produced per min per signaler), the population density $(\mathrm{CFU} / \mathrm{mL})$, and the resident time ( $\mathrm{min})$ of the signaler (Fig 5b). In cases in which the signaler population density evolves over time, the predicted concentration of $3 \mathrm{OC} 6 \mathrm{HSL}(\mathrm{nM})$ at time $\mathrm{t}$ can be calculated by multiplying the production rate ([HSL] $(\mathrm{nM})$ produced per min per signaler) to the antiderivative of the signaler density $(\mathrm{CFU} / \mathrm{mL})$ over $\mathrm{t}=0$ to $\mathrm{t}(\mathrm{min})$.

Applying the model to the analysis of the in vitro co-cultures of the signaler and the responder demonstrates how it provides further understanding of the system. Three sets of the $S$. Typhimurium signaler-E. coli responder co-cultures with ATC were prepared, with different initial densities of the signaler inoculated (Fig $5 \mathrm{c}$ ). The signaler growth curve was obtained based on the $\mathrm{CFU} / \mathrm{mL}$ values of the signaler at $\mathrm{t}=0,1,2 \mathrm{~h}$. By applying the model, I could calculate the signal production rate by the population and the total accumulated concentration of the signal at any given time (Fig $5 \mathrm{~d})$. At the end of the co-culture $(\mathrm{t}=2 \mathrm{~h})$, the percentage of the switched ON responders was also determined by blue-white screening. One set with the lowest signaler density resulted in $50 \%$ of the responder switched ON and the other two sets with the higher signaler densities resulted in $95 \%$ of the responder switched ON (Fig 5d). As expected, the negative controls with the responder alone in ATC or the responder-signaler co-cultures without ATC remained OFF. The application of the model can thus complement the time course dosage response characterization of the responder (Fig $4 \mathrm{a}, 4 \mathrm{~b}$ ) by providing information on how the responder switches $\mathrm{ON}$ in conditions in which the concentration of the signal changes as the signaler population fluctuates (Fig 5d). 


\section{Figure 5}

a

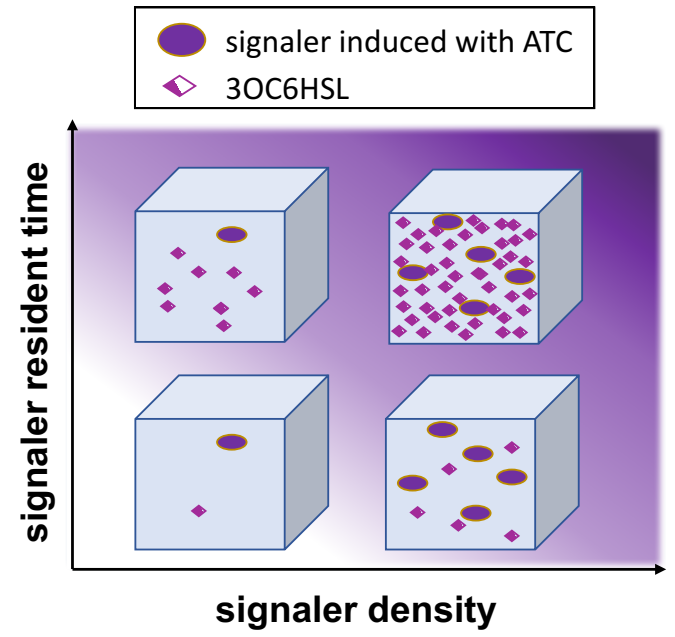

b

\section{E. coli signaler}

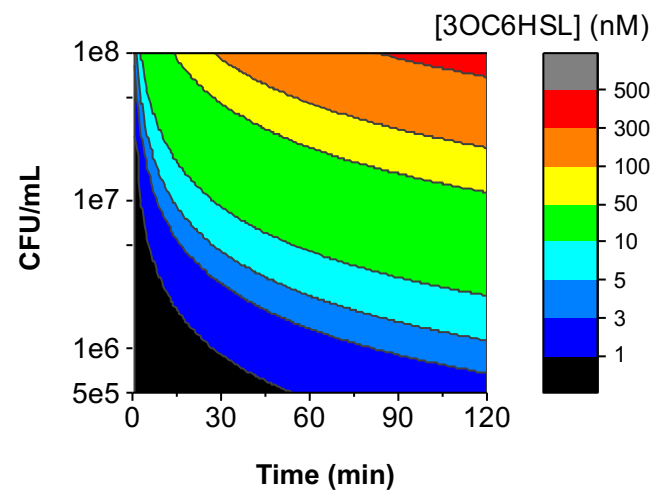

S. Typhimurium signaler

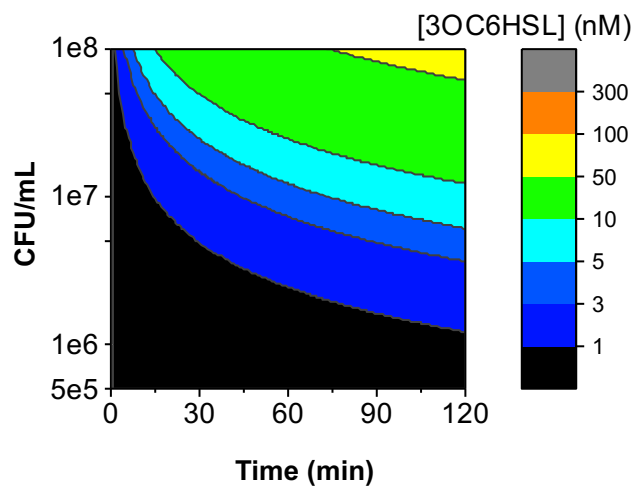

c

signaler-responder co-cultures

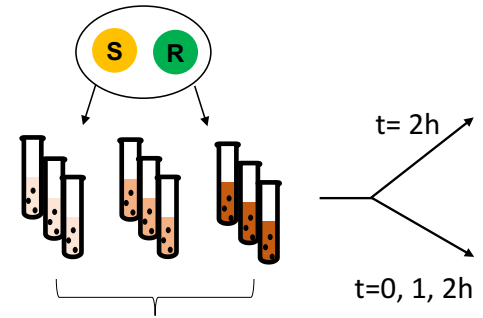

Different starting signaler densities
Find responder switched ON

Select for responder

(LB+strep+kan+Xgal).

Count $\%$ blue colonies.

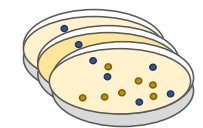

Find changes in signaler CFU/mL Screen for signaler (LB+cam+strep+Xgal+20nM 30C6HSL). Count white colonies.

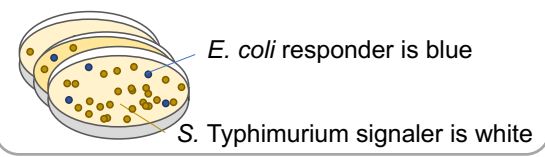


Figure 5 (Continued)

d
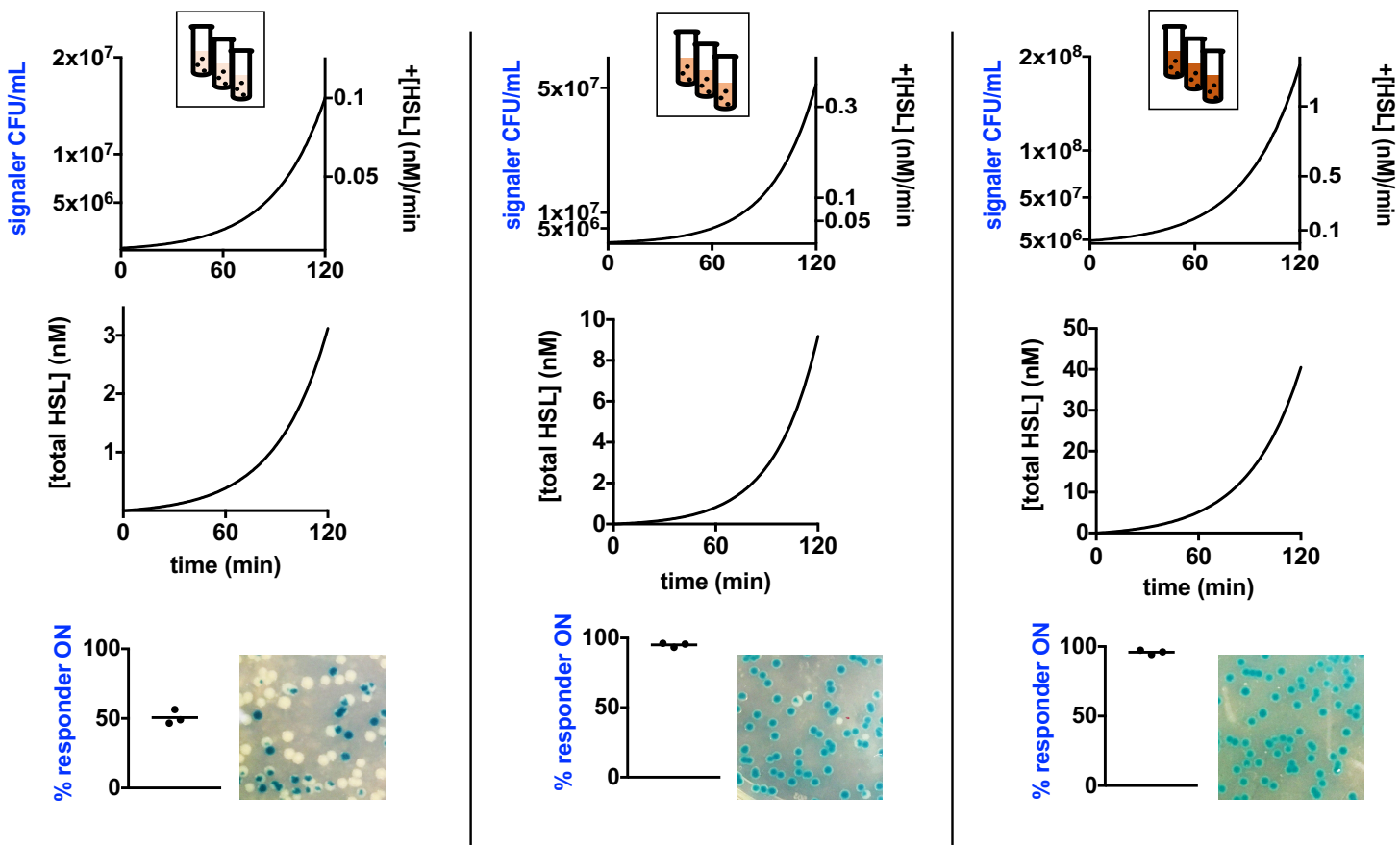

Model on the dynamic changes of the environment shaped by the signaler and its application to the in vitro co-cultures. a Abstraction on how the signal increases with higher signaler population density and the resident time in the microenvironment. b Predicted concentrations of the signal when the signaler population density is stable over time. The Y-axis denotes stable population densities and the heat map shows the predicted signal concentrations. $\mathbf{c}$ Procedure of the $S$. Typhimurium signaler- $E$. coli responder co-cultures. The cells were cocultured with shaking in LB+ATC. Three sets had different starting signaler densities. The signaler $\mathrm{CFU} / \mathrm{mL}$ values were obtained at $\mathrm{T}=0,1,2 \mathrm{~h}$ to get the signaler growth curves. The percentage of the switched $\mathrm{ON}$ responders was determined at $\mathrm{t}=2 \mathrm{~h}$. $\mathbf{d}$ Each column corresponds to one set of triplicate co-cultures, with different starting signaler densities. From left to right: samples with increasing starting signaler densities. Blue axes were experimentally determined; black axes were obtained by applying the model to the experimentally determined signaler growth curves. Top row: experimentally determined signaler growth curves (left Y-axis) and the predicted signal production rates by the population (right $\mathrm{Y}$-axis). Middle row: predicted total accumulated signal concentrations. Bottom row: experimentally determined percentage of switched ON responders at $\mathrm{t}=2 \mathrm{~h}$. Bars indicate means. Pictures show the indicator plates for the responder blue-white screening. 


\section{$\underline{\text { Methods }}$}

\section{Engineering the $E$. coli signaler and the responder}

The $E$. coli signaler was engineered using the sense-signal element synthesized as a gBlock (IDT), with $\sim 60 \mathrm{bp}$ homology arms to target the intergenic region between $\operatorname{araB}$ and $\operatorname{araC}$. The element has the sequence of Tn10 from the 3' end of tetR up until the start of tetA. Aliivibrio fischeri MJ1 strain's luxI, codon-optimized (IDT) for E. coli, was put in the place of tetA. 100ng of the gBlock was electroporated into the recombineering-competent strain of E. coli, TB10 (Johnson et al., 2004). Transformants were selected on LB+ampicillin 100ug/mL. In every recombineering step in this study, single colonies were picked and re-streaked twice before they were used in subsequent steps. The P1vir lysate from the transformed TB10 was used to transduce the NGF strain of $E$. coli to make the signaler. The E. coli NGF responder was made by introducing the Lux-trigger element into an existing NGF strain containing the memory element (Kotula et al., 2014). The Lux-trigger element was synthesized as a gBlock (IDT) with the following specifics. The luxR of the A. fischeri MJ1 was codon-optimized for E. coli and put downstream of the $\mathrm{Placl} \mathrm{Q}^{\mathrm{Q}}$ promoter and a synthetic RBS. The native cro gene from the bacteriophage lambda was put downstream of the A. fischeri MJ1's PluxI promoter and a synthetic RBS (part number BBa_B0029, iGEM Registry of Standard Biological Parts). PluxI and $\mathrm{Placl} \mathrm{Q}^{\mathrm{Q}}$ were separated by $\sim 80$ bp of random, buffering sequences. The gBlock was cloned into the pDR08 plasmid, a temperature-sensitive plasmid with arabinose-inducible genes for sitespecific recombination using the $\mathrm{Tn} 7$ transposon elements. After growing the electroporated cells on plates with $\mathrm{LB}+10 \mathrm{mM}$ arabinose $+12.5 \mathrm{ug} / \mathrm{mL}$ chloramphenicol at $30^{\circ} \mathrm{C}$ for two days, single colonies were picked and passaged twice on $\mathrm{LB}+25 \mathrm{ug} / \mathrm{mL}$ chloramphenicol at $42^{\circ} \mathrm{C}$ to cure the 
plasmids. The integration of the Lux-trigger element was confirmed via chloramphenicol resistance and the plasmid curing via ampicillin susceptibility.

\section{Engineering the $S$. Typhimurium signaler and the responder}

I used an attenuated strain of $S$. Typhimurium built partly by the laboratory of Dr. James Slauch and my colleague, Marika Ziesack. Dr. Slauch kindly provided his strain JS481, which has a knockout of the main parts of SPI-1 (Ellermeier et al., 2005). The knockout of SPI-2 was first created by Marika Ziesack in a recombineering-competent strain of LT2 using a gBlock to replace SPI-2 with a kanamycin-resistance cassette flanked by FRT sequences. The cassette was then P22-transduced into the strain JS481. I introduced a temperature-sensitive plasmid encoding FLPase to remove the kanamycin-resistance cassette and cured the plasmids after confirming kanamycin sensitivity. The resulting, attenuated strain of LT2 was sequence-confirmed to be: $\Delta 3009865-3044887$ (of SPI-1) and $\Delta 1501112-1462122$ (of SPI-2), of the NCBI sequence ID AE006468.2). The sense-signal element and the Lux-trigger element were first integrated into the recombineering-competent LT2 strain (Lau et al., 2017) and was subsequently P22transduced into the above attenuated strain background to make the signaler. The elements were synthesized as gBlocks, with $100 \mathrm{bp}$ homology arms targeting the intergenic locus between yafB and yafC. The $S$. Typhimurium signaler resistant to streptomycin $(>300 \mathrm{ug} / \mathrm{mL})$ was obtained by exposing cells to increasing concentrations of streptomycin and selecting for spontaneously arising resistant clones. For the memory element, I used the strain of $S$. Typhimurium with the memory element made by a former Silver lab member, S. Jordan Kerns to produce P22 lysates. He had built the CRIM P21 integration plasmid and propagated it in the M+R-Salmonella strains DB7011 (gift of the David Botstein lab). He thus integrated the element into the SA2009 
strain from the Salmonella Genetic Stock Center and P22-transduced first into the LT2 strain. Using this strain, I further P22-transduced the memory element into the attenuated LT2 strain. The $S$. Typhimurium Lux-trigger element was incorporated into the recombineering-competent LT2 strain and P22-transduced into the attenuated strain harboring the memory element to generate the $S$. typhimurium responder.

\section{Time course dosage responses of the $E$. coli and the $S$. Typhimurium responders} An overnight culture of the responder was diluted 1:4000 into LB+cam or LB+strep broth and grown for $1.5 \mathrm{hrs}$ (E. coli responder) or $2.5 \mathrm{hrs}$ (S. Typhimurium responder) to pass the lag phase and enter the exponential phase of growth. The culture was then divided into multiple tubes, to which 3OC6HSL (Sigma Aldrich, k3007; stock solutions were prepared using dimethyl sulfoxide and kept at $-20^{\circ} \mathrm{C}$ ) was added to various final concentrations. From each tube, 100uLx3 was distributed into three wells of a U-shaped, low-attachment 96-well plate for a triplicate reaction. Cells were grown at $37^{\circ} \mathrm{C}$ with shaking throughout the procedure. Between $\mathrm{t}=0-4 \mathrm{~h}$, a small volume from each well was taken out hourly and serially diluted in PBS to aim for $\sim 10^{3}-10^{4} \mathrm{CFU} / \mathrm{ml} .50-200 \mathrm{uL}$ were bead-plated onto $\mathrm{LB}+\mathrm{kan} 50 \mathrm{ug} / \mathrm{mL}+$ strep300ug $/ \mathrm{mL}+\mathrm{Xgal}$ $60 \mathrm{ug} / \mathrm{mL}$. The percentage of blue colonies was determined.

\section{Quantification of the 30C6HSL production by the $E$. coli and the $S$. Typhimurium signalers}

The overnight culture of the signaler was subcultured in LB+strep broth for $1.5 \mathrm{~h}$ (E. coli) or $2.5 \mathrm{~h}$ (S. Typhimurium) to pass the lag phase and enter the exponential phase of growth. The signaler cells were then exposed to ATC $(100 \mathrm{ng} / \mathrm{mL})$ for $1 \mathrm{~h}(E$. coli $)$ or $2 \mathrm{~h}(S$. Typhimurium) to produce 
$3 \mathrm{OC} 6 \mathrm{HSL}$ at $37^{\circ} \mathrm{C}$ with shaking. Small volumes were taken out and plated to count the $\mathrm{CFU} / \mathrm{g}$ at $\mathrm{t}=0,30 \mathrm{~min}, 1 \mathrm{~h}$ (E. coli) or $\mathrm{t}=0,1 \mathrm{~h}, 2 \mathrm{~h}(\mathrm{~S}$. Typhimurium) and obtain the growth curves. At the endpoint, cells were pelleted and the supernatants were sterile-filtered ( $0.2 \mathrm{um})$. The supernatants were diluted $1: 10,20,30,40,50$ into $\mathrm{LB}+$ strep broth containing the pre-subcultured $(\sim 1.5 \mathrm{~h})$, post-lag phase $E$. coli responder in the exponential phase. The supernatant+responder mixtures were incubated at $37^{\circ} \mathrm{C}$ with shaking for $1.5 \mathrm{~h}$ for the biosensor reaction. I countered possible day-to-day or batch-to-batch variations in the responder switching $\mathrm{ON}$, by exposing the same batch of the responder cells to the 3OC6HSL standards in parallel, to serve as the reference dosage response of that day. At the end of the $1.5 \mathrm{~h}$ exposure, the responder cells were diluted and plated onto LB+kan+strep+Xgal to count the percentage of blue colonies. I used Graphpad Prism to interpolate the concentrations of 30C6HSL of the diluted supernatants. First, I input the percentage of blue colony of the responder when exposed to different concentration of the 3OC6HSL standards for non-linear fitting. Then, I input the percentage of blue colony of the responder when exposed to the diluted signaler supernatants to obtain the interpolated concentrations of $3 \mathrm{OC} 6 \mathrm{HSL}$ in these diluted supernatants. Multiplying these values by the dilution factors, I obtained the concentrations in the undiluted supernatants. These concentrations were used to calculate the rates of production of 3OC6HSL by the E. coli and the $S$. Typhimurium signalers using the following formula:

The number of 3OC6HSL molecules produced per signaler cell per $\mathrm{min}=$ $6[30 \mathrm{C} 6 \mathrm{HSL}] 6 \mathrm{nMHf}$ the undiluted supernatantH $\times$ 6number of molecules in $1 \mathrm{~mL}$ of $1 \mathrm{nM}$ solutionH $\int_{0}^{60} 6$ signaler growth curve equation ${ }^{*} d t$ 
*growth curve equation was obtained using Excel, with the $\mathrm{X}$-axis as $\mathrm{t}=$ min and the $\mathrm{Y}$-axis as $\mathrm{CFU} / \mathrm{mL}$. The experimentally determined $\mathrm{CFU} / \mathrm{mL}$ values at the three time points mentioned above were used to generate the exponential trendline and the corresponding equation.

\section{In vitro co-cultures of the $S$. Typhimurium signaler and the $E$. coli responder}

Overnight cultures (LB+strep 200ng $/ \mathrm{mL}$ ) of the attenuated $S$. Typhimurium signaler and the $E$. coli responder were subcultured $(1: 4000, \mathrm{LB}+$ strep $100 \mathrm{ng} / \mathrm{mL})$ for $2.5 \mathrm{~h}$ at $37^{\circ} \mathrm{C}$. The signaler was then diluted $1 / 20,1 / 10$, and $1 / 2(\mathrm{LB}+$ strep $100 \mathrm{ng} / \mathrm{mL})$, to which the responder $(1 / 500$ of the subculture) and ATC (100ng/mL) was added and vortexed to mix. Two sets of negative controls were prepared: i) responder alone (1/500 dilution) with ATC $(100 \mathrm{ng} / \mathrm{mL})$ and ii) responder (1/500 dilution) and the signaler ( $1 / 2$ dilution) without ATC. This point was set as $\mathrm{t}=0$ and each of the three co-culture sets and the negative controls was distributed into three wells of a Ushaped, low-attachment 96-well plate for triplicate reactions. The plate was incubated at $37^{\circ} \mathrm{C}$ on

a plate shaker at $\sim 1000 \mathrm{rpm}$. At $\mathrm{t}=0,1,2 \mathrm{~h}$, small volumes of the samples were diluted in PBS and plated on $\mathrm{LB}+\mathrm{cam}+$ strep $+\mathrm{Xgal}+20 \mathrm{nM} 3 \mathrm{OC} 6 \mathrm{HSL}$ to screen for the $S$. Typhimurium signaler as white colonies. At $t=2 h$, the samples were also plated onto $L B+k a n+$ strep $+X g a l$ plates to count the percentage of blue colonies of the $E$. coli responder. The signaler growth curves were obtained using Excel by plotting exponential trendlines ( $\mathrm{X}$-axis as $\mathrm{t}=$ min; $\mathrm{Y}$-axis as $\mathrm{CFU} / \mathrm{mL}$ ) and corresponding equations based on the experimentally determined $\mathrm{CFU} / \mathrm{mL}$ values at $\mathrm{t}=0,1$, $2 \mathrm{~h}$. 
Table 2

Bacterial strains list

\begin{tabular}{|c|c|c|c|}
\hline Strain \# & Identity & Engineered signatures & Note \\
\hline PAS703 & $\begin{array}{l}\text { E. coli } \mathrm{NGF} \\
\text { signaler }\end{array}$ & $\begin{array}{l}\text { - } \quad \text { sense-signal element, ampR } \\
\text { - } \quad \text { strepR (rpsL mutation) }\end{array}$ & Completed strain \\
\hline PAS704 & $\begin{array}{l}\text { E. coli } \mathrm{NGF} \\
\text { responder }\end{array}$ & $\begin{array}{l}\text { - } \quad \text { Lux-trigger element, camR } \\
\text { - } \quad \text { memory element } \\
\text { (Kotula et al, 2016), kanR } \\
\text { - } \quad \text { strepR (rpsL K42R) }\end{array}$ & Completed strain \\
\hline PAS705 & $\begin{array}{c}S . \text { Typhimurium } \\
\text { attenuated LT2 signaler }\end{array}$ & $\begin{array}{ll}\text { - } & \text { LT2 sense-signal element, camR } \\
\text { - } & \text { strepR (spontaneous mutant } \\
\text { obtained; genetic cause } \\
\text { unknown) } \\
\text { - } & \text { deletions in SPI-1, } 2 \\
\end{array}$ & Completed strain \\
\hline PAS706 & $\begin{array}{l}S . \text { Typhimurium } \\
\text { attenuated LT2 responder }\end{array}$ & $\begin{array}{l}\text { - } \quad \text { LT2 Lux-trigger element, camR } \\
\text { - Memory element, kanR } \\
\text { - } \\
\text { strepR (spontaneous mutant } \\
\text { obtained; genetic cause } \\
\text { unknown) } \\
\text { - deletions in SPI-1, } 2\end{array}$ & Completed strain \\
\hline PAS707 & $\begin{array}{l}\text { E. coli } \mathrm{TB} 10 \\
\text { signaler }\end{array}$ & - $\quad$ sense-signal element, ampR & $\begin{array}{l}\text { Produced by recombineering } \\
\text { the sense-signal element into } \\
\text { TB10. P1 lysate from this } \\
\text { strain was used in making } \\
\text { PAS703. }\end{array}$ \\
\hline PAS708 & $\begin{array}{l}\text { E. coli NGF } \\
\text { signaler }\end{array}$ & $\begin{array}{l}\text { - } \quad \text { sense-signal element, ampR } \\
\text { - } \quad \text { strepS }\end{array}$ & $\begin{array}{c}\text { PAS703 was made by } \\
\text { transducing strepR element } \\
\text { into this strain }\end{array}$ \\
\hline PAS709 & $\begin{array}{l}S . \text { Typhimurium } \\
\text { attenuated LT2 }\end{array}$ & - deletions in SPI-1, 2 & $\begin{array}{l}\text { Attenuated chassis used in } \\
\text { making PAS705, } 706 .\end{array}$ \\
\hline PAS710 & $\begin{array}{l}S \text {. Typhimurium LT2 } \\
\text { for recombineering }\end{array}$ & $\begin{array}{l}\text { - Recombineering-cassettes in } \\
\text { the genome } \\
\text { - gentR }\end{array}$ & $\begin{array}{l}\text { Lau et al., 2017, referred as } \\
\text { "IRE." } \\
\text { Used to recombineer elements } \\
\text { and produce P22 lysates. }\end{array}$ \\
\hline PAS711 & $\begin{array}{c}S . \text { Typhimurium } \\
\text { attenuated LT2 } \\
\text { w/ memory element }\end{array}$ & - Memory element, kanR & \\
\hline PAS712 & $\begin{array}{c}S . \text { Typhimurium } \\
\text { attenuated LT2 with Lux- } \\
\text { trigger element }\end{array}$ & - Lux-trigger element, camR & \\
\hline PAS713 & E. coli $\mathrm{NGF}$, strepR & - $\quad$ strepR & $\begin{array}{l}\text { PAS222 was P1-transduced } \\
\text { for an } r p s L \text { mutation (strepR) }\end{array}$ \\
\hline
\end{tabular}


Table 3

DNA elements list

\begin{tabular}{|c|c|c|c|}
\hline Used for: & Element name & Selection markers & $\begin{array}{c}\text { ACS Synthetic Biology } \\
\text { Registry } \\
\text { Part ID }\end{array}$ \\
\hline E. coli signaler & sense-signal element & ampR & ACS_00736 \\
\hline E. coli responder & $\begin{array}{c}\text { Lux-trigger element } \\
\text { (in Tn7 integration } \\
\text { plasmid) }\end{array}$ & $\begin{array}{c}\text { camR (and also } \\
\text { ampR before } \\
\text { curing the } \\
\text { plasmids) }\end{array}$ & ACS_000735 \\
\hline $\begin{array}{c}S . \text { Typhimurium } \\
\text { signaler }\end{array}$ & LT2 sense-signal element & camR & ACS_000738 \\
\hline $\begin{array}{c}S . \text { Typhimurium } \\
\text { responder }\end{array}$ & LT2 Lux-trigger element & kanR & \\
\hline
\end{tabular}

\section{To use the elements for your research}

The easiest strategy would be finding the relevant DNA sequences deposited to the ACS Synthetic

Biology Registry, synthesizing the major parts (include 50-100bp homology arms to target your genomic locus of interest), transforming it into recombineering-competent strains of $E$. coli or $S$. Typhimurium and subsequently P1 (E. coli) or P22 (S. Typhimurium)-transducing into the final strains of interest.

\section{Strain specifics}

PAS707 has the TB10 background and expresses recombineering cassettes at higher temperature. Thus, when using PAS707 to produce $\mathrm{P} 1$ lysates, grow at $30^{\circ} \mathrm{C}$ and let the lysate production run for a longer time $(>4 \mathrm{~h})$ than what typical protocols call for at $37^{\circ} \mathrm{C}(1-2 \mathrm{~h})$.

Also note that from our observation, the NGF strain does not successfully produce viable P1 lysates and should not be used as a donor strain in transduction 


\section{Chapter 3.}

\section{Characterizing the information transfer system in the mammalian gut}

\section{Chapter summary}

The results from the previous chapter demonstrated that the engineered bacteria performed with high sensitivity and robustness in vitro. The real-life complex environment of the gut is expected to pose many additional challenges to the performance of synthetic circuits. To test whether the engineered strains can establish functional inter-cellular signaling the mammalian gut using acyl-HSL, I deployed the intra-species information transfer system consisting of the E. coli signaler and the E. coli responder, and inter-species information transfer system consisting of the $S$. Typhimurium signaler and the E. coli responder. Conventional and gnotobiotic mice were used as animal models. Both intra-and inter-species information transfer systems demonstrated successful inter-cellular signaling, suggesting the potential of acyl-HSLmediated signaling in creating artificial communication for the engineered gut consortia. The systems also revealed more complex response in animals, including mouse-to-mouse variability and an interesting $\mathrm{O}_{\mathrm{R}}$ mutant arising in the gnotobiotic mouse experiment. 


\section{$\underline{\text { Results }}$}

The intra-species information transfer system using the $E$. coli signaler and the $E$. coli responder in the conventional mice

The intra-species information transfer system deployed to the mouse gut demonstrated successful communication between the engineered $E$. coli signaler and the $E$. coli responder in a complex real-world environment. I delivered the two engineered strains into 12 conventional BALB/c mice by oral gavage ( 8 experimental, 4 control). Starting from two days after the gavage, the experimental group was given ATC $(0.1 \mathrm{mg} / \mathrm{mL}$ in drinking water) for two days. The control group was not given ATC at any point (Fig 6a). Each day, fecal samples were collected and analyzed on selective plates to count the $\mathrm{CFU} / \mathrm{g}$ values of the signaler and the responder, as well as the percentage of switched ON responders (Fig 6b, Methods). One day after the gavage and before ATC was given, the responder was OFF in all mice except one in the experimental group, which showed a low level (1\%) of switching ON. After one day of dosing with ATC, five out of the eight mice in the experimental group showed clear signs of the responder switched ON, ranging from 13 to $74 \%$ in different mice. The difference in switching ON between the preATC and post-ATC samples in the experimental group was statistically significant (MannWhitney $U$ Test, $\mathrm{p}<0.05)$. After two days on ATC, the same five mice still had the responder switched ON to various degrees (Fig 6c). To check whether the responder cells that remained OFF in the ATC-treated mice had lost their function as biosensors, I picked the post-transit white colonies (OFF state) of the responders and re-streaked onto induction plates containing 3OC6HSL and Xgal. These white colonies then gave rise to blue colonies upon induction with 3OC6HSL, confirming that the responder cells were functional. There was an average 5-fold drop in the colonization of the responder between the days 0 and 3 (Fig 7a). There was no clear 
pattern between the percentage of switched $\mathrm{ON}$ responders and the colonization level or the ratio between the two strains (Fig 7b, 7c). The responder in the four mice in the negative control group without ATC remained OFF until the end of the study (Fig 6c). These data indicate successful information transfer between the signaler and the responder in the majority of mice.

\section{Figure 6}

a

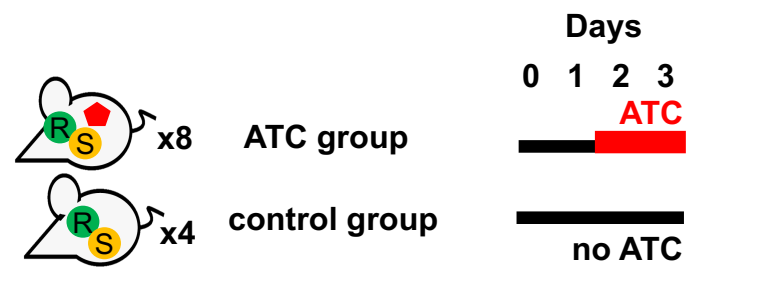

Day 0: gavaged E. coli signaler and E. coli responder b

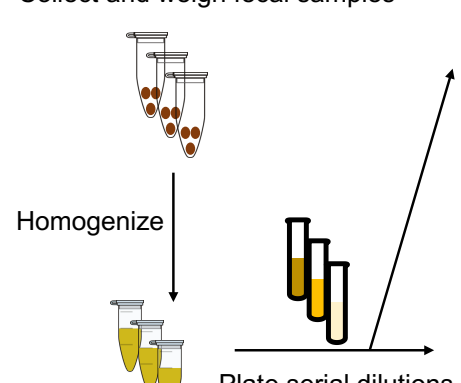

Plate serial dilutions
E. coli signaler analysis LB+amp+strep: count total (signaler CFU/g

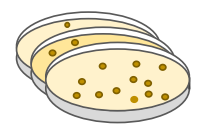

E. coli responder analysis LB+cam+kan+strep+Xgal: count total (responder CFU/g count $\%$ blue (\% switched ON

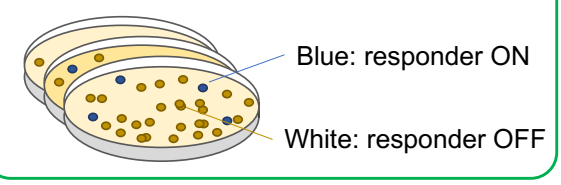

c

ATC group (days 2, 3)

$\checkmark$ control group (no ATC)

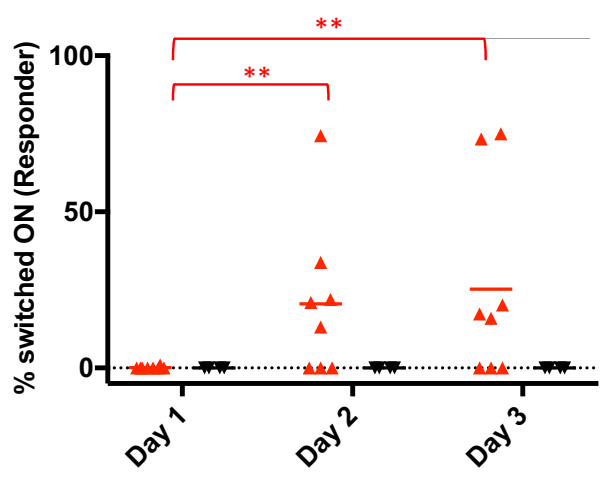

The $E$. coli to $E$. coli intra-species information transfer system in the gut. a Schematics of the animal study. b Downstream analysis of the daily fecal samples. Fecal samples from each mouse were weighed, homogenized, serially diluted, and plated onto selective plates for the $E$. coli signaler or the $E$. coli responder. c The switching $\mathrm{ON}$ of the responder in the experimental group and the control group. Bars indicate means. ** indicates $\mathrm{p}<0.05$ in Mann-Whitney U tests on the ATC group, comparing Day 1 (pre-ATC) and Days 2, or 3 (post-ATC). 
Figure 7

a
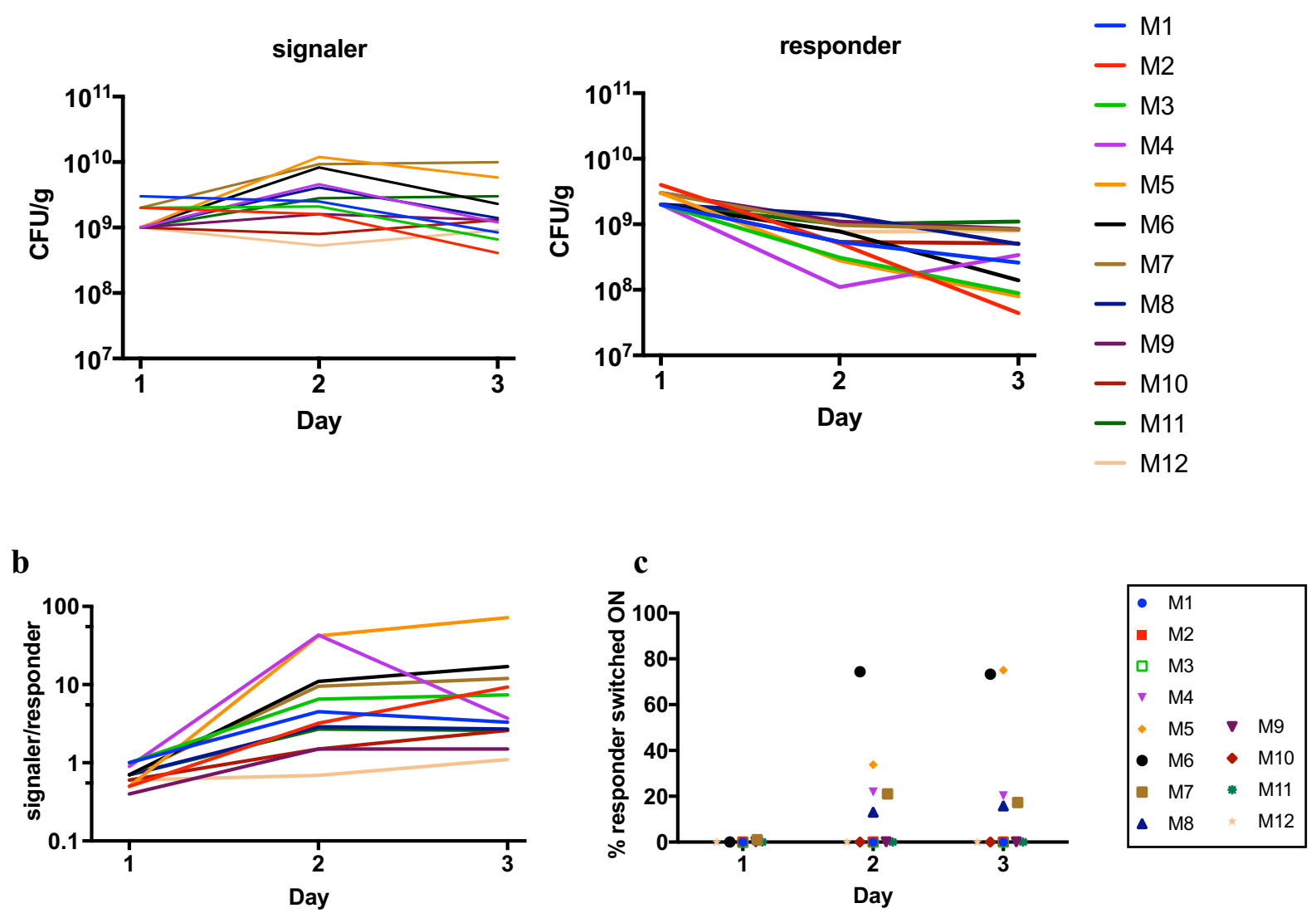

Fluctuations and the percentages of switched $\mathrm{ON}$ responders are not correlated in the intra-species information transfer between the $E$. coli signaler and the $E$. coli responder in the mouse gut. a Fluctuation in the $\mathrm{CFU} / \mathrm{g}$ values of the $E$. coli signaler and the $E$. coli responder. b Fluctuation in the signaler/responder ratios (CFU/g over CFU/g). c The percentage of switched ON responders of individual mice. M1-M8 are in the ATC group and received ATC water starting after the sample collection on Day 1; M9-M12 did not receive ATC. 


\section{The inter-species information transfer system using the $S$. Typhimurium signaler and the}

\section{E. coli responder in the conventional mice}

The inter-species information transfer system consisting of the $S$. Typhimurium signaler and the E. coli responder also demonstrated successful communication in the mouse gut. I used the study design described above with minor modifications on the duration of the experiment and the selective plates used (Fig 8a, 8b). The result indicated that 7 out of 8 mice in the experimental group had the responder switched ON with ATC but not without ATC, with slight daily variations. The percentages of switched $\mathrm{ON}$ responders ranged from $0.5 \%$ to $86 \%$ in different mice. (Fig 8c, Fig 9c). The difference in switching ON between the pre-ATC and post-ATC samples in the experimental group was statistically significant (Mann-Whitney U Test, $\mathrm{p}<0.01$ ). All mice in the negative control group without ATC showed the responder in the OFF state throughout the experiment (Fig 8c). Unexpectedly, one mouse of the experimental group switched $\mathrm{ON}$ to around $50 \%$ one day before ATC was given (Fig 8c, Fig 9c). To examine whether this switching ON was caused by mutations within the engineered parts, I sequenced the entire Lux-trigger and the memory elements of the switched $\mathrm{ON}$ responder cells in this mouse but found no mutation (see Conclusion for discussion). From tallying the CFU/g each day, I did observe a significant drop in the E. coli responder densities throughout the study. The responder density dropped 30-fold on average by day 9, while the $S$. Typhimurium signaler maintained its density (Fig 9a). Interestingly, the mouse with the unexpected high switching ON before ATC showed the most rapid and dramatic decrease in the responder population, with the density dropping more than 1000-fold by day 9 (Fig 9a). There was no clear pattern between the percentages of switched $\mathrm{ON}$ responders and the $\mathrm{CFU} / \mathrm{g}$ values or the ratios between the two species in other mice (Fig 9b, 9c). 


\section{Figure 8}

a

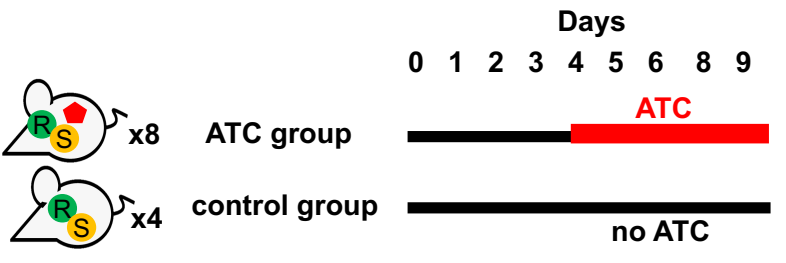

Day 0: gavaged S. Typhimurium signaler and E. coli responder

c

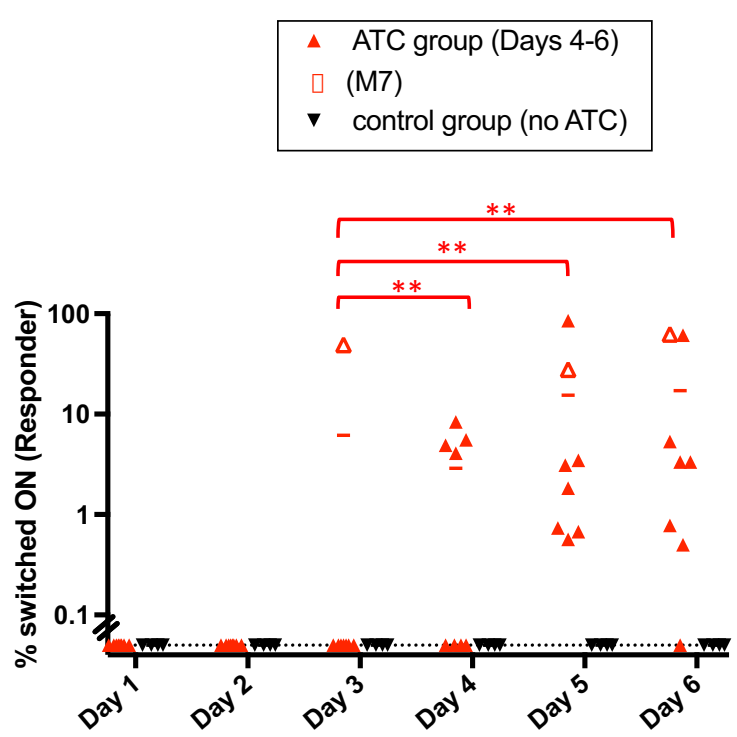

Collect and weigh fecal samples

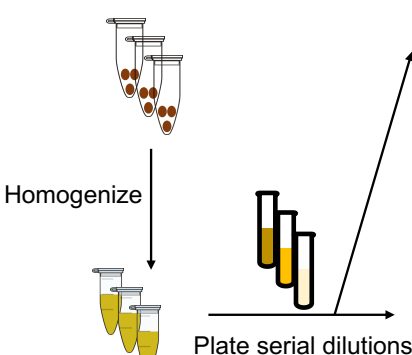

Plate serial dilutions
S. Typhimurium signaler analysis LB+cam+strep+20nM 30C6HSL+Xgal: count white signaler $\mathrm{CFU} / \mathrm{g}$ )

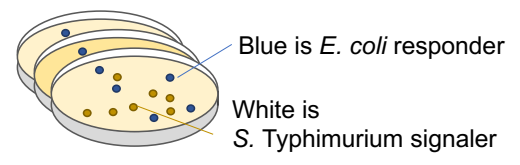

E. coli responder analysis LB+cam+kan+strep+Xgal: count $\%$ blue $\%$ switched $O N$ ) count total responder CFU/g)

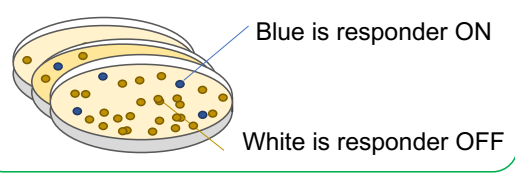

The $S$. Typhimurium to $E$. coli inter-species information transfer system in the gut. a

Schematics of the animal study. The 8 mice in the experimental group received ATC after Day 3 in drinking water. The 4 mice in the control group were not given ATC. Fecal samples were collected for the downstream analysis. b Downstream analysis of the fecal samples. The addition of $20 \mathrm{nM}$ of $3 \mathrm{OC} 6 \mathrm{HSL}$ in plates induces all E. coli responder cells to form blue colonies, while the $S$. Typhimurium signaler cells remain white. c The detected switching ON of the responder cells from the mouse fecal samples. M7 is the outlier that switched ON one day before ATC was given (see main text and Fig 9c). The percentage for M7 on Day 4 could not be counted due to an unexpected drop in the $\mathrm{CFU} / \mathrm{g}$. All data points below $0.1 \% \mathrm{ON}$ were plotted together on the dotted line for simplicity. Bars indicate means. ** indicates $\mathrm{p}<0.01$ in Mann-Whitney $U$ tests on the experimental group, comparing Day 3 (pre-ATC) and Days 4, 5, or 6 (post-ATC). Comparison between Day 3 and Day 4 was done excluding M7, since M7 tallying was not successful on Day 4. Comparison between Day3 and Days 5 or 6 included the M7 data. 


\section{Figure 9}

a
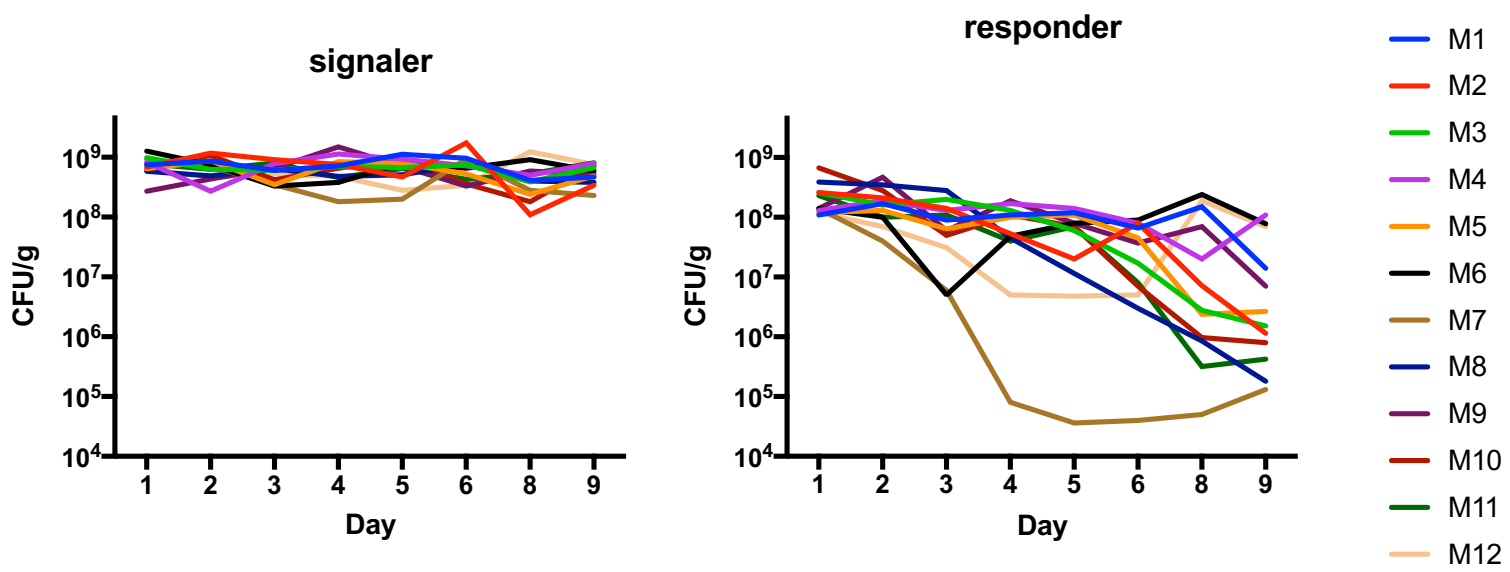

b

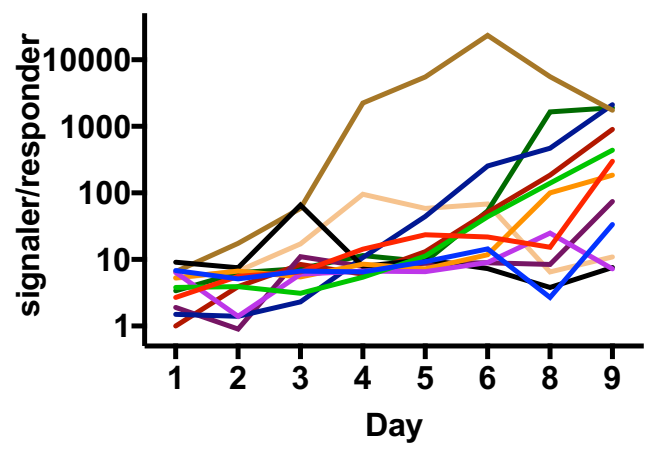

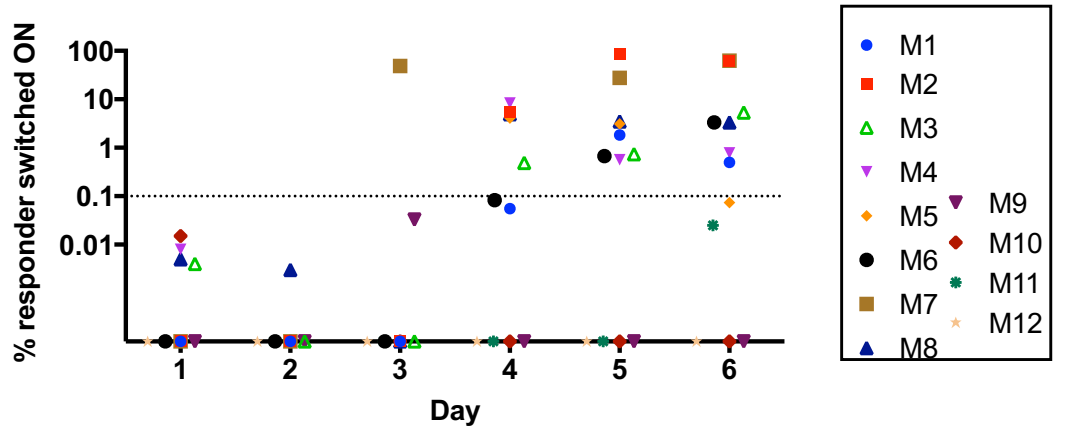

Fluctuations and the percentage of switched $O N$ responders are not correlated in the interspecies information transfer between the $S$. Typhimurium signaler and the $E$. coli responder in the mouse gut. a Fluctuation in the CFU/g values of the $S$. Typhimurium signaler and the $E$. coli responder. b Fluctuation in the signaler/responder ratios (CFU/g over CFU/g). c The percentage of the switched ON responder cells of individual mice. M1-M8 are in the ATC group and received ATC water starting after the sample collection on Day 3; M9-M12 did not receive ATC. 


\section{The intra-species information transfer system using the $E$. coli signaler and the $E$. coli responder in gnotobiotic mice}

The original motivation of introducing the signaler and the responder to the germ-free background was based on a hypothesis that there would be an increased response and decreased variability of switching $\mathrm{ON}$, given the absence of background microbiota that might interfere with the system. However, the experiment using the intra-species information transfer system with the $E$. coli signaler and the $E$. coli responder in germ-free mice led to unexpected results and insights. For these experiments, I collaborated with Dr. Lynn Bry and Dr. Georg Gerber at Brighman and Women's Hospital to design the experiment and assisted by two scientists in their laboratories who maintained the germ-free mice, gavaged the bacteria, and collected fecal samples daily for me to analyze.

The results indicated that when the responder is given to the germ-free mice, there is an unexpected rise of the switched ON responder cells even before the ATC is administered. Two isolators were used to contain Group A and Group B mice. Each isolator has an isolated environment and prevents unintentional introduction of bacteria. For this study, two isolators were used for Group A and B, each one containing five individually caged female 6-week old Swiss Webster mice (Fig 10a). After routine confirmation of germ-free status of the isolators and the mice, all mice in Group A were gavaged with $\sim 10^{8} \mathrm{CFU}$ each of the signaler and the responder, while all mice in Group B were gavaged with $\sim 10^{8} \mathrm{CFU}$ of the responder alone (Day 0). Our original plan was to not provide ATC to either group between Days 1-7, and provide ATC to both groups between Days 8-14 (Fig 10a). I expected that both Group A and Group B would have the responders OFF without ATC during Days 1-7 since the signaler is not induced. I expected that once ATC is administered, Group A would show responder in the ON state, while 
Group B would have the responder in the OFF state due to the absence of the signaler. Daily fecal samples were weighed, homogenized, serially diluted, and plated to count the CFU/g of the signaler and the responder separately using selective plates, and to count the percentage of blue colonies of responders (Fig 10b). On Day 1, I observed very low percentages of blue colonies in a few mice (less than $0.1 \%$ ) that might be very low background switching ON (Fig 10c). Surprisingly, the percentages of blue colonies significantly increased by next day (Fig 10c). In Group A, the percentages were below 5\%. In Group B, the values ranged from 15 to $32 \%$. The percentages continued to increase in both groups so that by Day 7, the Group A showed 1-17\% switching ON, while the Group B showed 90-98\% switching ON in different mice (Fig 10c). Because the switching ON unexpectedly occurred without ATC administration, I decided to end the study at Day 7.

I first tested and confirmed that the unexpected blue colonies on the LB-kan-strep-Xgal selective plates were indeed E. coli responder and not accidentally introduced contaminating bacteria that are naturally $l a c+$. I randomly picked 10 blue colonies and conducted colony PCR to amplify the synthetic part of the responder. The presence of the amplicon of the expected size confirmed the identity as the responder. Also, I indirectly confirmed that the white colonies on LB + kan + strep + Xgal were also responder cells, not contaminating cells. This was achieved by directly plating the diluted fecal samples onto LB+20nM 3OC6HSL + Xgal plates and LB+kan+strep+Xgal (Fig 10b). The former had only blue colonies, while the latter had a mix of blue and white colonies. Since all the white colonies could be switched ON by exogenously provided 3OC6HSL, it is highly unlikely that they are not my engineered responder cells.

Exposing the responder to fecal samples of germ-free Swiss Webster mice (without any bacteria introduced) showed that there is no endogenous 30C6HSL or its agonist in the fecal 
samples within the detection limit $(1 \mathrm{nM})$. Fecal pellets of the germ-free Swiss Webster mice were homogenized in PBS. 500uL of the supernatant + kan was used to inoculate the responder. As a control, $\mathrm{LB}+$ kan with the responder was used. The next day, the responders were plated onto $\mathrm{LB}+\mathrm{kan}+\mathrm{cam}+$ strep $+\mathrm{Xgal}$. The responder was previously tested to detect around $1 \mathrm{nM}$ of 3OC6HSL when incubated overnight with the solution. There was no switching ON. The negative result suggests that 4 pellets $/ 500 \mathrm{uL}$ contained less than $1 \mathrm{nM}$ of $3 \mathrm{OC} 6 \mathrm{HSL}$.

To better understand the unexpected switched ON phenotype, I re-streaked the blue colonies and found that there were two different phenotypes. Ten blue colonies on the $\mathrm{LB}+\mathrm{kan}+\mathrm{cam}+$ strep + Xgal plates on Day 2 were randomly picked from various mice and restreaked onto new LB+kan+cam + strep + Xgal plates. Five of these blue colonies gave rise to a homogenous population consisting only of blue colonies, upon the first, second, and third restreaks. The other five blue colonies gave rise to a mix of blue colonies and white colonies upon re-streaking. The first type, which continuously gave rise to only blue colonies upon serial restreaking, is not observed when a wild type responder is temporarily induced ON with 3OC6HSL before re-streaking. Therefore, I suspected that genetic mutations might be responsible for this first type of blue colonies.

Sequencing analysis of the blue colonies that consistently gave rise to only blue colonies revealed that there was indeed a shared mutation in the $\mathrm{O}_{\mathrm{R}} 1$ operator region and, in some cases, additional mutations in $c I^{\text {ind }}$. I sequenced blue colonies originating from the Day 2 samples of mice M2 and M4 of Group A and the mouse M7 of Group B. The memory element was amplified via colony PCR and its two major functional areas were sequenced to check for any mutation (Fig 10d). Two controls were also sequenced. The first control was a responder colony originating from the mouse M2 on Day 2 that functionally behaved as a wild type responder: it 
formed a white colony during the initial plating onto LB+kan+cam+strep + Xgal, and could be induced to switch ON with exogenous 3OC6HSL during re-streaking. The second control was a responder colony from a fresh streak of the original responder glycerol stock, which was stored in the $-80^{\circ} \mathrm{C}$. Result showed that while the controls did not have any mutation in the memory element, all three blue colonies that had constitutively switched ON phenotype shared a single base pair mutation $(\mathrm{G} \rightarrow \mathrm{A})$ in the $\mathrm{O}_{\mathrm{R}} 1$ operator (Fig 10d). I found that this base pair has been reported in studies on the bacteriophage lambda before, including the "KM69" mutation with the same $\mathrm{G} \rightarrow \mathrm{A}$ substitution that reduces the expression out of the $\mathrm{P}_{\mathrm{RM}}$ promoter, presumably by affecting the binding of $\mathrm{CI}$ onto the $\mathrm{O}_{\mathrm{R}} 1$ (Gussin et al., 1987; Meyer et al., 1980). In addition, the colony from M2 had a deletion in the 373th nucleotide that created an early stop codon at the 131 th amino acid position of $c I^{\text {ind }}$. The colony from M9 also had a non-silent, L66P mutation within $c I^{\text {ind- }}$. Although they were not tested in isolation from the concurrent $\mathrm{O}_{\mathrm{R}} 1$ mutation, it is possible that they also negatively affect the ability of the CI protein from creating a stable OFF state (Fig 10d). Since the colony from M4 had a wild type sequence of $c I^{\text {ind-}}$, however, such additional mutation in this gene does not seem to be necessary to create this persistently switched ON phenotype.

Lastly, the fluctuations of the CFU/g (of feces) of the signaler and the responder revealed that the responder colonization is negatively affected by the presence of the signaler (Fig 10e). Between Day 1 and Day 7, the responder density dropped nearly 100-folds in M1-5, while it increased $\sim 10$-fold in M6-10. In comparison, the signaler densities in M1-M5 were relatively stable around $10^{9} \mathrm{CFU} / \mathrm{g}$ (Fig 10e). 


\section{Figure 10}

a

Group A in isolator - (M- -M5):

signaler and responder

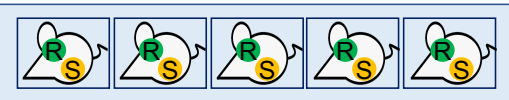

Group B in isolator 2 (M6-M- 0):

responder

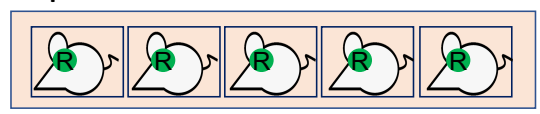

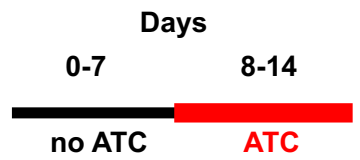

Day 0: gavaged E. coli signaler and $E$. coli responder

b

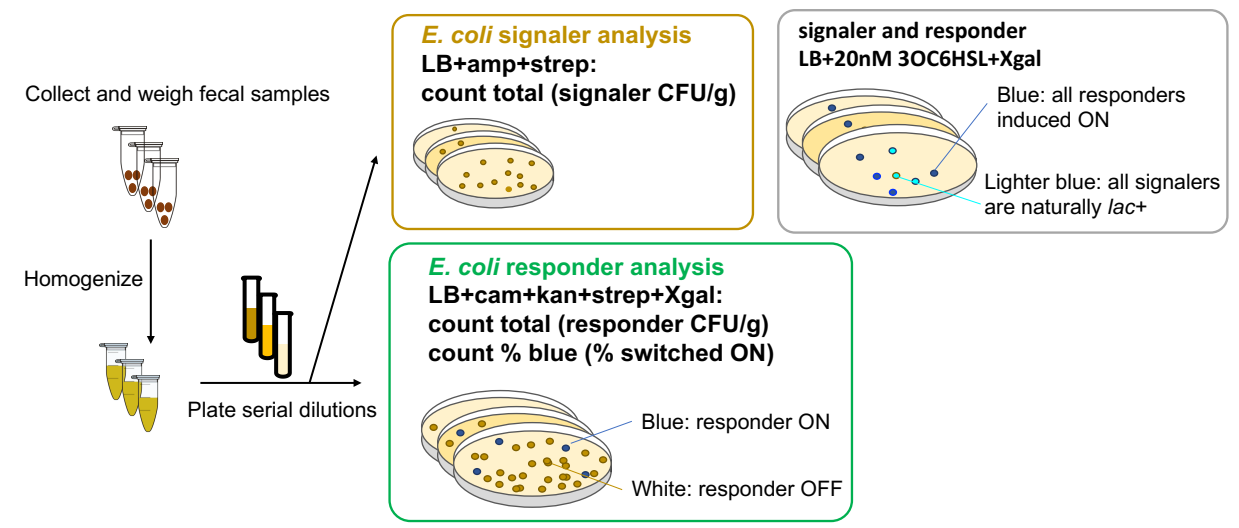

c
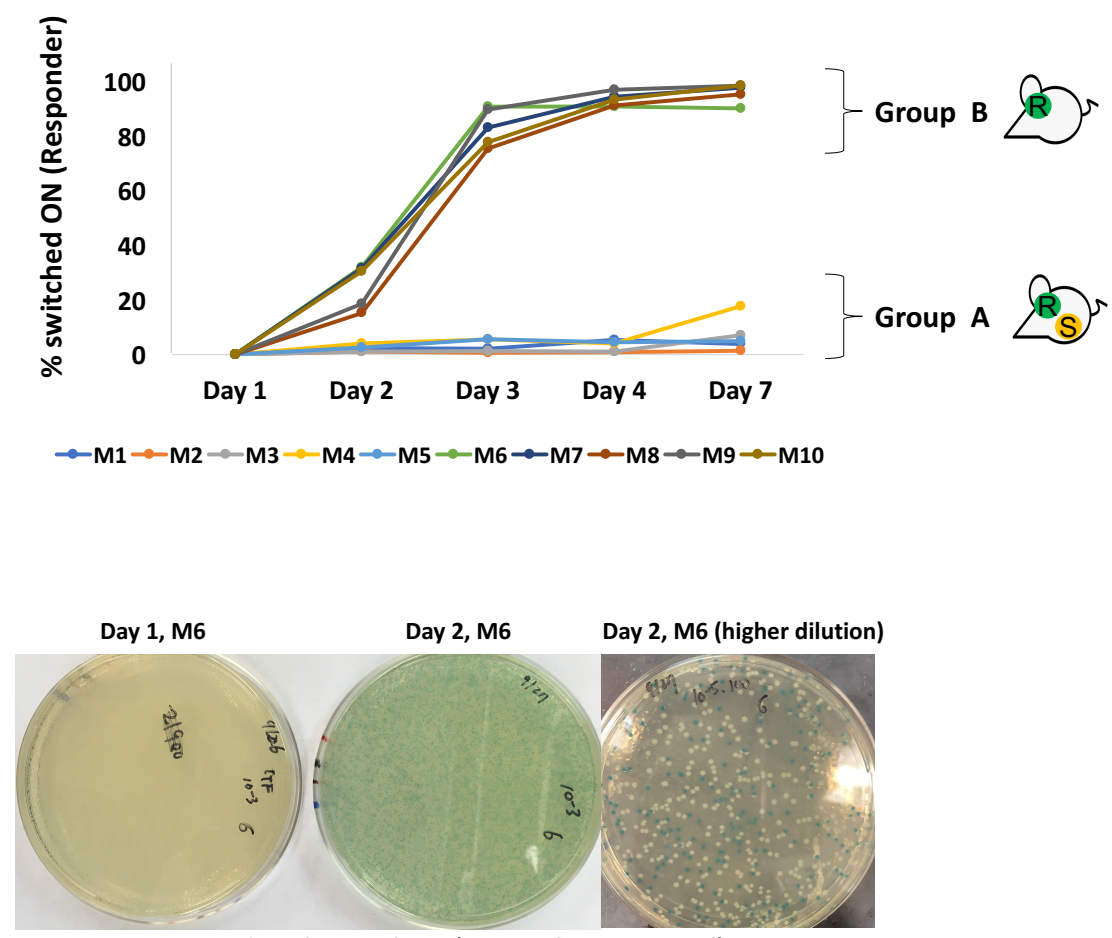

responder selective plates (LB+cam+kan+strep+Xgal) 


\section{(Figure 10 continued)}

d

\begin{tabular}{|c|c|c|c|}
\hline $\begin{array}{l}\text { Control } \\
\text { responder WT }\end{array}$ & 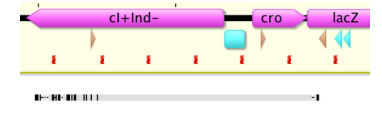 & no mutation & white colonies \\
\hline M2 & $\left.\right|_{\text {Early stop codon results }} ^{\text {cl+tnd- }}$ & $\begin{array}{l}\mathrm{O}_{R} 1 \text { mutation: } \\
\text { TACCTCTGGCG }(G \rightarrow A) \text { TGATA } \\
\qquad c^{\text {Ind- }} \text { mutation: } \\
\text { deletion of nucleotide } 373 ; \\
\text { creates an early stop codon } \\
\text { at the } 131 \text { th codon }\end{array}$ & blue colonies only \\
\hline M4 & 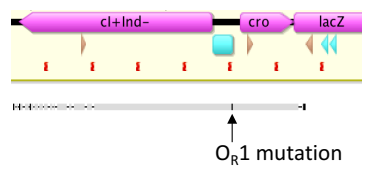 & $\begin{array}{c}\mathrm{O}_{\mathrm{R}} 1 \text { mutation: } \\
\text { TACCTCTGGCG }(\mathrm{G} \rightarrow \mathrm{A}) \text { TGATA }\end{array}$ & blue colonies only \\
\hline M9 & 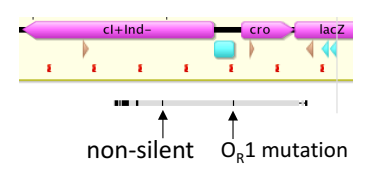 & $\begin{array}{c}\mathrm{O}_{R} 1 \text { mutation: } \\
\text { TACCTCTGGCG }(G \rightarrow \text { A)TGATA } \\
\text { cl'nd- mutation: } \\
\text { L66P (CTT to TTT) }\end{array}$ & blue colonies only \\
\hline
\end{tabular}

$\mathbf{e}$

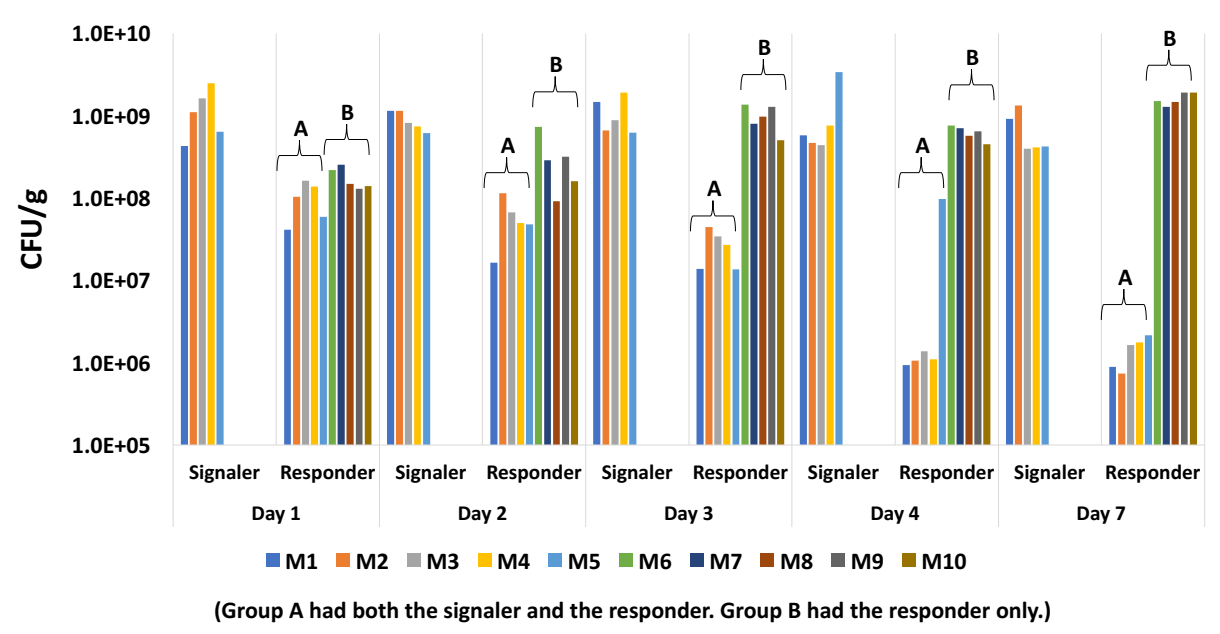

The $E$. coli to $E$. coli intra-species information transfer system in the gnotobiotic mice. a Experimental design of the gnotobiotic mouse experiment. b Downstream analysis of the fecal samples. c Top: switching ON of the responder, from Days 1-7. Bottom: example of the change in the responder switching ON in Group B between Day 1 and Day 2. d Mutation analysis on the unexpected blue colonies that continuously give rise to blue colonies only upon re-streaking onto $\mathrm{LB}+\mathrm{cam}+\mathrm{kan}+$ strep + Xgal. Sequencing of the major functional regions of the memory element $\left(c I^{\text {ind- }}\right.$ and $\mathrm{O}_{\mathrm{R}}$ ) revealed a shared mutation in $\mathrm{O}_{\mathrm{R}} 1$ in all three colonies originating from three different mice. Two of these also had one non-silent mutation each in $c I^{\text {ind }}$. No mutation was found in the responder controls. e Fluctuation of the CFU/g values of the signaler and the responder and the negative influence of the signaler on the responder colonization in Group A. 


\section{$\underline{\text { Methods }}$}

\section{Intra-species information transfer in the mouse gut}

The Harvard Medical School Animal Care and Use Committee approved all animal study protocols. Female BALB/c Elite mice of 6-week old (Charles River company) were acclimatized to the facility for 2 weeks before the start of experiments. Each cage housed four mice (M1-M4, M5-M8, and M9-M12) under the microisolator FST system in the BSL-1 facility. Mice were fed with regular high-fiber, low-fat diet (PicoLab Rodent Diet, 5053) and drinking water with strep $(0.5 \mathrm{mg} / \mathrm{mL}$ streptomycin sulfate (USP grade, VWR), 5\% sucrose; $0.2 \mathrm{uM}$ sterile-filtered) starting from half a day before the gavage to the end of the experiment (Day 3). All 12 mice were given approximately $10^{8} \mathrm{CFU}$ each of the $E$. coli signaler and the $E$. coli responder by oral gavage on Day 0. The experimental group (M1-M8) were provided with drinking water that contains ATC $(0.1 \mathrm{mg} / \mathrm{mL}$ of ATC (Sigma Aldrich), $0.5 \mathrm{mg} / \mathrm{ml}$ strep, $5 \%$ sucrose, $0.2 \mathrm{um}$ filter-sterilized; water bottles were foil-wrapped due to ATC photosensitivity) during the treatment period (starting after the sample collection on Day 1). Special water was freshly made at least every $48 \mathrm{~h}$. Fecal samples were collected daily, weighed, suspended in PBS to $100 \mathrm{mg} / \mathrm{mL}$, and vortexed thoroughly to homogenize. The samples were centrifuged at low speed $(100 \mathrm{~g}, 15 \mathrm{~min})$ to pellet down large fibers and insoluble particles. The supernatant in the upper part of the tube was serially diluted $\left(10^{-3}-10^{-6}\right.$-folds) in PBS and bead-plated $(100 \mathrm{uL}$ on $10 \mathrm{~cm}$ selective plates $)$ for the E. coli signaler $(\mathrm{LB}+\mathrm{amp} 50 \mathrm{ug} / \mathrm{mL}+$ strep $300 \mathrm{ug} / \mathrm{mL})$ or the $E$. coli responder $(\mathrm{LB}+\mathrm{cam}$ 25ug/mL+kan 50ug/mL+strep 300ug/mL+Xgal 60ug/mL). Samples collected before the oral gavage resulted in no growth on the selective plates, confirming the absence of the background flora resistant to the antibiotics used to select for the engineered cells. 


\section{Inter-species information transfer in the mouse gut}

The general information regarding the animal treatment and the sample collection is the same as described above, except the mice were acclimatized to the facility for 1 week and housed in the BSL-2 facility. Four mice were housed per cage (M1-4, M5-8, M9-12). Approximately 2x10 CFU each of the $S$. Typhimurium signaler and the $E$. coli responder were delivered into all 12 $\mathrm{BALB} / \mathrm{c}$ mice by oral gavage on Day 0 . Drinking water with strep was given to all mice starting from 3 days before the gavage to the end of the experiment. The experimental group (M1-M8) were provided with drinking water with ATC during the treatment period (starting after the sample collection on Day 3). The signaler CFU/g was determined by counting the white colonies on LB+cam+strep+Xgal+20nM 3OC6HSL plates, which distinguish the $S$. Typhimurium signaler from the E. coli responder by inducing the latter to switch $\mathrm{ON}$ and form blue colonies. The responder CFU/g and the percentage of switched $\mathrm{ON}$ responders were determined on the LB + kan + cam + strep + Xgal plates. Samples collected before the oral gavage resulted in no growth on the selective plates, confirming the absence of the background flora resistant to the antibiotics used to select for the engineered cells. Note that I measured the percentages of switched ON responders until Day 6 but tallied the CFU/g until Day 9. In analysis, the percentages of blue colonies of $0.1 \%$ or above were considered bona-fide switching ON.

\section{Intra-species information transfer system in gnotobiotic mice}

One week before the gavage (Day -7), 10 female 5-week old Swiss Webster germ-free mice were transferred to two isolators. M1-M5 were put into one isolator (Group A) and M6-M10 into the other (Group B). On Day -4, fecal samples were collected from each isolator to confirm sterility. For oral gavage, overnight cultures of the signaler and the responder were frozen in aliquots. One 
vial of each was thawed and triplicate-plated to find the $\mathrm{CFU} / \mathrm{mL}$ values of the de-frosted aliquots. Based on these values, on Day 0, the aliquots were thawed and diluted in PBS to deliver $\sim 10^{8} \mathrm{CFU}$ each of the signaler and the responder to Group A mice, and $\sim 10^{8} \mathrm{CFU}$ of the responder to Group B mice. The total volume of the inoculum per mouse was $200 \mathrm{uL}$. The selective plate for the responder was $\mathrm{LB}+\mathrm{kan}+\mathrm{cam}+\mathrm{strep}+\mathrm{Xgal}$. The percentages of switched $\mathrm{ON}$ responders were obtained by counting the percentages of blue colonies. The selective plate for the signaler was $\mathrm{LB}+\mathrm{amp}+$ strep. To test for endogenous 3OC6HSL or agonists in germ-free mice, four fecal pellets of the germ-free Swiss Webster mice were homogenized in $1 \mathrm{~mL}$ of PBS and centrifuged for $7 \mathrm{~min}$ at $100 \mathrm{rpm}$ on a desktop centrifuge. 500uL of the supernatant + kan was used to inoculate the responder. As a control, $500 \mathrm{uL}$ of the $\mathrm{LB}+\mathrm{kan}$ with the responder was used. 
Chapter 4.

Conclusion 
Given the close association of the gut micobiota with the mammalian host, it can be useful to engineer gut bacteria to monitor the health of the host, report on infections and diseases, and provide enhanced nutrition or treatments in situ. Using the intra- and inter-species information transfer systems, I demonstrated that Gram-negative bacterial quorum sensing can be repurposed into an artificial direct communication method for the mammalian gut microbiota. The overall design strategies included integrating all synthetic cassettes as genome-integrated single copies to increase stability and reduce the metabolic burden of the synthetic parts as well as incorporating a genetic switch for post-transit analysis through analysis of bacteria in fecal samples.

Programmable inter-microbial communication is a crucial component towards building multiplexed systems through engineered gut consortia. The strengths of interconnected engineered cells that coordinate their actions through secreted signals have previously been reported in in vitro systems (Ausländer et al., 2018; Tamsir, et al., 2011). These systems, consisting of networks of engineered bacteria or human cells, could accomplish computations and create cellular patterns that are more complex than the sum of the individual parts (Ausländer et al., 2018; Tamsir, et al., 2011). Similarly, I believe that signal-mediated communication is a fundamental aspect of interaction that will allow engineered gut consortia to perform more advanced tasks in vivo.

The E. coli responder demonstrated several strengths as an in vivo biosensor to record and report the evidence of communication between the signaler and the responder. First, the $E$. coli responder has high sensitivity to 3OC6HSL, with a low-nM detection limit. Second, the responder switches ON after a physiologically achievable duration of exposure to the signal. When the responder cells in the exponential phase of growth were exposed to 3OC6HSL in vitro, 
the minimum required time of exposure for marked switching to occur was $1 \mathrm{~h}$, which is within the residency time of bacteria in the gut (Myhrvold et al., 2015). Finally, the responder is equipped to report even transient communication in the gut, by recording the detection of the signal using a genetic switch.

Compared to the $E$. coli responder, the $S$. Typhimurium responder was less sensitive and slower to switch ON when induced with 3OC6HSL. While it was not the focus of the present study to further optimize the $S$. Typhimurium responder, there are possible explanations for the difference observed in the two species. First, it has been reported that the $S$. Typhimurium SdiA protein, a LuxR-homolog, can bind to 3OC6HSL and activate the PluxI promoter. (Michael et al., 2001). If the SdiA-3OC6HSL complex is less efficient than the LuxR-3OC6HSL at activating the transcription at PluxI, the presence of SdiA would negatively affect the performanzce of the Lux-trigger element. Second, since the memory element is based on a genetic switch of the bacteriophage lambda, which natively targets E. coli, this genetic part may be less efficient in $S$. Typhimurium than in E. coli.

The E. coli and $S$. Typhimurium signalers demonstrated the production of 3OC6HSL with high efficiency and capacity when induced with ATC. Many in vitro synthetic systems have been built using acyl-HSLs as the inter-cellular signals among the engineered bacteria. However, these systems overexpress the $l u x I$ homologs from multi-copy plasmids and do not include quantification of the signal production. As such, it was unclear whether bacteria that do not naturally use quorum sensing can be engineered to produce physiologically effective levels of acyl-HSLs when produced by a single, genomically integrated copy of luxI. The rate of production by the signaler using the responder as the biosensor confirmed that it is possible. 
Both the intra-and inter-species information transfer systems indicated that the signaler could successfully communicate to the responder using acyl-HSL in the gut, but also showed interesting complexities not observed in vitro. First, as with most animal experiments of this type, there was mouse-to-mouse variation in response to ATC. Although the majority of mice in the ATC group showed switching ON, a few mice remained OFF despite receiving ATC for a few days. I do not think this is due to reversion from the ON to the OFF state, since previous studies established the stability of the ON state (Kotula et al., 2014; Riglar et al., 2017). Alternatively, in the mice that showed no response, the signaler cells might not have been exposed to sufficient levels of ATC, either because these mice did not consume enough ATCcontaining water, or because there are variations in the host metabolism of ATC. Second, among the mice that responded to ATC, the percentages of switched ON responders varied. The degree of switching did not correlate with the CFU/g of the signaler or the ratio between the signaler and the responder. It is possible that the variation is caused by the differences in the background microbiota, the host metabolism, or the amount of ATC that successfully reached the gut in each mouse. Lastly, in the inter-species study, I observed an unexpected switching ON to $\sim 50 \%$ without ATC in one mouse. Prior studies using the memory element over longer periods of up to 6 months have shown no mutation in the engineered bacteria that led to the untriggered ON state (Riglar et al., 2017). It is possible that the switching ON might have resulted from the bona fide detection of acyl-HSLs or agonists that were present.

The overall difference in the responder switching ON between the ATC-receiving group and the control group of mice demonstrated that communication can happen successfully using 3OC6HSL as the inter-cellular signal in the gut. The average percentage of switched ON responders was higher in the intra-species system than in the inter-species system (Fig 6c, 8c). 
This difference may be partly due to the production rate of 3OC6HSL being higher in the E. coli signaler than in the $S$. Typhimurium signaler (Table 1). It is also possible that the attenuated $S$. Typhimurium signaler colonizes at a further distance away from the $E$. coli responder than does the $E$. coli signaler, thus reducing the effective concentration of 3OC6HSL that the responder is exposed to.

The unexpected rise of the switched ON responder cells without ATC in the gnotobiotic mouse experiment may suggest an interesting growth advantage of lactose-utilizing bacteria in the mouse gut. This hypothesis is based on the two aspects of the result. First, this taking-over of the ON responder cells without ATC was not observed in conventional mice. Since Group B without the signaler also switched ON, the untriggered switching ON was not due to the signaler unexpectedly producing $3 \mathrm{OC} 6 \mathrm{HSL}$ in the absence of ATC in the germ-free setting. It is possible that the common $\mathrm{O}_{\mathrm{R}} 1$ mutation either arose after the gavage, or the mutation was present in small number in the liquid overnight culture that was used in the gavage. What is more interesting is that regardless of whether the mutant was already present in the gavage stock or freshly arose in each mouse, the percentages of switched ON responders in Group B that had the responder alone were much higher than those in Group A that had both the signaler and the responder. Given that both groups were gavaged with the same responder overnight prep, there cannot be a significant difference in the input responder to both groups. Thus, it seems that the presence of the signaler deterred the increase of the percentage of untriggered switching ON. The responders that switched ON might have had growth advantage over the switched OFF responder cells when there are no other bacteria that utilize lactose. In conventional mice, there are many species that are naturally $l a c+$ and utilize lactose. Therefore, there may be only low level of lactose available in the gut. In the gnotobiotic mice Group A, which had both the signaler and the responder, the 
signaler is naturally lac+ and is expected to also decrease the available lactose level. In the gnotobiotic mice Group B, which has only the responder cells, there would be more lactose available in the gut. Thus, the switched ON responder cells might have growth advantage over the OFF cells by utilizing lactose. If this interpretation is correct, it would also suggest that the germ-free setting is not a neutral setting, and while it is a powerful tool, the behaviors of single or few species studied in the germ-free setting may be quite different from their behaviors in more complex settings with native flora.

Finally, these are remaining questions that I hope get addressed in the future. First, how does the information transfer system performs in vivo, when the mice are not treated with an antibiotic (streptomycin) to give colonization advantage to the engineered bacteria? Preliminary testing from the Silver lab seems to suggest that the E. coli NGF strain background persists for days or weeks without streptomycin treatment, but with the CFU/g values being orders of magnitude lower. It would be interesting to see whether the local densities of the signaler and the responder can still facilitate successful information transfer using HSL as the secreted signal and what the low threshold CFU/g is for the communication to occur. Second, how does the information transfer system function in larger mammals? The ultimate engineering motivation behind devising artificial communication for the gut bacteria is to identify and devise a system that can efficiently function in the human gut. The size of the human gut is much bigger and longer than that of the mouse gut. This difference in the magnitude may create additional challenges for engineering inter-bacterial communication that can efficiently function in larger mammals. It would be therefore informative to test the information transfer system in larger animals such as dogs and cows, using their native gut $E$. coli as the chasses. Finally, does establishing HSLs as artificial communication signals for the engineered bacteria make the host 
more susceptible to the invasion of pathogens that naturally utilize HSLs? Before HSLs pass the test as artificial inter-bacterial signal in the gut for real-life applications, further animal studies should test how pre-colonization of the AHL-using engineered bacteria affect the host vulnerability to gut pathogens.

In summary, I repurposed Gram-negative quorum sensing in a non-native environment to create programmable information transfer system for cellular interactions and communication in the mammalian gut. This system provides a basis for further understanding of inter-bacterial interactions in an otherwise hard-to-study environment as well as a basis for further investigation of the potential of acyl-HSLs as inter-cellular signaling molecules of engineered gut consortia. 


\section{References}

Ausländer, D., Ausländer, S., Pierrat, X., Hellmann, L., Rachid, L., Fussenegger, M. (2018). Programmable full-adder computations in communicating three-dimensional cell cultures. Nat. Methods 15, 57-60.

Ayres, J.S., Trinidad, N.J., Vance, R.E. (2012). Lethal inflammasome activation by a multidrugresistant pathobiont upon antibiotic disruption of the microbiota. Nat. Med. 18, 799-806.

Bakken, J.S., Borody, T., Brandt, L.J., Brill, J.V., Demarco, D.C., Franzos, M.A., Kelly, C., Khoruts, A., Louie, T., Martinelli, L.P., Moore, T.A., Russell, G., Surawicz, C., Fecal Microbiota Transplantation Workgroup. (2011). Treating Clostridium difficile infection with fecal microbiota transplantation. Clin. Gastroenterol. Hepatol. 9, 1044-1049.

Baumler, A.J. and Sperandio, V. (2016). Interactions between the microbiota and pathogenic bacteria in the gut. Nature 535, 85-93.

Basu, S., Gerchman, Y., Collins, C.H., Arnold, F.H., Weiss, R. (2005). A synthetic multicellular system for programmed pattern formation. Nature 434, 1130-1134.

Borkowski, O., Ceroni, F., Stan, G.B., Ellis, T. (2016). Overloaded and stressed: whole-cell considerations for bacterial synthetic biology. Curr. Opin. Microbiol. 33, 123-130.

Brenner, K., Karig, D.K., Weiss, R., Arnold, F.H. (2007). Engineered bidirectional communication mediates a consensus in a microbial biofilm consortium. Proc. Natl. Acad. Sci. USA $104,17300-17304$.

Chan, C.T.Y., Lee, J.W., Cameron, D.W., Bashor, C.J., Collins, J.J. (2015). 'Deadman' and 'Passcode' microbial kill switches for bacterial containment. Nat Chem Biol 12, 82-88.

Clemente J.C., Ursell, L.K., Parfrey, L.W., Knight, R. (2012). The impact of the gut microbiota on human health: an integrative view. Cell 148, 1258-1279.

Daeffler, K.N., Galley, J.D., Sheth, R.U., Ortiz-Velez, L.C., Bibb, C.O., Shroyer, N.F., Britton, R.A., Tabor, J.J. (2017). Engineering bacteria thiosulfate and tetrathionate sensors for detecting gut inflammation. Mol. Sys. Bio. 13, 923.

De Palma, G., Lynch, M.D., Lu, J., Dang, V.T., Deng, Y., Jury, J., Umeh, G., Miranda, P.M., Pigrau Pastor, M., sidani, S., Pinto-Sanchez, M.I., Philip, V., McLean, P.G., Hagelsieb, M.G., Surette, M.G., Bergonzelli, G.E., Verdu, E.F., Britz-McKibbin, P., Neufeld, J.D., Collins, S.M., Bercik, P. (2017). Transplantation of fecal microbiota from patients with irritable bowel syndrome alters gut function and behavior in recipient mice. Sci. Transl. Med. 379, eaaf6367.

Dodd, D., Spitzer, M.H., Van Treuren, W., Merrill, B.D., Hryckowian, A.J., Higginbottom, S.K., Le, A., Cowan, T.M., Nolan, G.P., Fischbach, M.A., Sonnenburg, J.L. (2017). A gut bacterial pathwy metabolizes aromatic amino acids into nine circulating metabolites. Nature 551, 648-652. 
Dyszel, J.L., Smith, J.N., Lucas, D.E., Soares, J.A., Swearingen, M.C., Vross, M.A., Young, G.M., Ahmer, B.M. (2010). Salmonella enterica serovar Typhimurium can detect acyl homoserine lactone production by Yersinia enterocolitica in mice. J. Bacteriol. 192, 29-37.

Earle, K.A., Billings, G., Sigal, M., Lichtman, J.S., Hansson, G.C., Elias, J.E., Amieva, M.R., Huang, K.C., Sonnenburg, J.L. (2015). Quantitative imaging of gut microbiota spatial organization. Cell Host Microbe 18, 478-488.

Ellermeier, C.D., Ellermeier, J.R., Slauch, J.M. (2005). HilD, HilC and RtsA constitute a feed forward loop that controls expression of the SPI1 type three secretion system regulator hilA in Salmonella enterica serovar Typhimuium. Mol. Microb. 57, 691-705.

Emge, P., Moeller, J., Jang, H., Rusconi, R., Yawata, Y., Stocker, R., Vogel, V. (2016). Resilience of bacterial quorum sensing against fluid low. Sci. Rep. 6, 33115.

Engebrecht, J., Nealson, K., Silverman, M. (1983). Bacterial bioluminescence: isolation and genetic analysis of functions from Vibrio fischeri. Cell 32, 773-781.

Everard, A., Belzer, C., Geurts, L., Ouwerkerk, J.P., Druart, C., Bindels, L.B., Guiot, Y., Derrien, M., Muccioli, G.G., Delzenne, N.M., de Vos, W.M., Cani, P.D. (2013). Cross-talk between Akkermansia muciniphila and intestinal epithelium controls diet-induced obesity. Proc. Natl. Acad. Sci. USA 110, 9066-9071.

Franklin, C.L., and Ericsson, A.C. (2017). Microbiota and reproducibility of rodent models. Lab. Anim. 46, 114-122.

Fuqua, C., Parsek, M.R., Greenberg, E.P. (2001). Regulation of gene expression by cell-to-cell communication: acyl-homoserine lactone quorum sensing. Annu. Rev. Genet. 35, 439-468.

Gimble, F. S., Sauer, R. T. (1986). $\lambda$ repressor inactivation: properties of purified Ind $^{-}$proteins in the autodigestion and RecA-mediated cleavage reactions. J. Mol. Biol. 192, 39-47.

Gimble, F. S., Sauer R. T. (1989). $\lambda$ repressor mutants that are better substrates for RecAmediated cleavage. J. Mol. Biol. 206, 29-39.

Gussin, G.N., Brown, S., Ferm, J., Matz, K. (1987). New mutations in the PRM promoter of bacteriophage lambda. Gene 54, 291-297.

Hsiao, E.Y., McBride, S.W., Hsien, S., Sharon, G., Hyde, E.R., McCue, T., Codelli, J.A., Chow, J., Reisman, S.E., Petrosino, J.F., Patterson, P.H., Mazmanian, S.K. (2013). Microbiota modulate behavioral and physiological abnormalities associated with neurodevelopmental disorders. Cell 155, 1451-1463.

Hwang, I.Y., Koh, E., Wong, A., March, J.C., Bentley, W.E., Lee, Y.S., Chang, M.W. (2016). Engineered probiotic Escherichia coli can enliminate and prevent Pseudomonas aeruginosa gut infection in animal models. Nat. Commun. 8, 15028. 
Johnson, J.E., Lackner, L.L., Hale, C.A., de Boer, P.A. (2004). ZipA is required for targeting of DMinC/DicB, but not DMinC/MinD, complexes to septal ring assemblies in Escherichia coli. J Bacteriol 186, 2418-2429.

Jovel, J., Patterson, J., Wang, W., Hotte, N., O'Keefe, S., Mitchel, T., Perry, T., Kao, D., Mason, A.L., Madsen, K.L., Wong, G.K.-S. (2016). Characterization of the gut microbiome using 16S shotgun metagenomics. Front. Microbiol. 7:459.

Kamada, N., cen, G.Y., Inohara, N., Nunez, G. (2013). Control of pathogens and pathobionts by the gut microbiota. Nat. Immunol. 14, 685-590.

Kim, S., Kim, H., Yim, Y.S., Ha, S., Atarashi, K., Tan, T.G., Longman, R.S., Honda, K., Littman, D.R., Choi, G.B., Huh, J.R. (2017). Maternal gut bacteria promote neurodevelopmental abnormalities in mouse offspring. Nature 549, 528-532.

Kotula, J.W., Kerns, S.J., Shaket, L.A., Siraj, L., Collins, J.J., Way, J.C., Silver, P.A. (2014). Programmable bacteria detect and record an environmental signal in the mammalian gut. Proc. Natl. Acad. Sci. USA 111, 4838-4843.

Lau, Y. H., Stirling, F., Kuo, J., Karrenbelt, M. A. P., Chan, Y. A., Riesselman, A., Horton, C. A., Schafer, E., Lips, D., Weinstock, M. T., Gibson, D. G., Way, J. C., Silver, P. A. (2017) Large-scale recoding of a bacterial genome by iterative recombineering of synthetic DNA. Nucleic Acids Res. 45, 6971-6980.

Luczynski, P., Neufeld, K-A. M., Oriach, C.S., Clarke, G., Dinan, T.G., Cryan, J.F. (2016). Growing up in a bubble: using germ-free animals to assess the influence of the gut microbiota on brain and behavior. Int. j. Neuropsychopharmacol. 19, pyw020.

Mark Welch, J.L., Hasegawa, Y., McNulty, N.P., Gordon, J.I., Borisy, G.G. (2017). Spatial organization of a model 15-member human gut microbiota established in gnotobiotic mice. Proc. Natl. Acad. Sci. USA 114, 9105-9114.

Marketon, M.M., Gronquist, M.R., Eberhard, A., Gonzalez, J.E. (2002). Characterization of the Sinorhizobium meliloti $\sin \mathrm{R} / \mathrm{sinI}$ locus and the production of novel $\mathrm{N}$-acyl homoserine lactones. J. Bacteriol. 184, 5686-5695.

Meyer, B.J., Maurer, R., Ptashne, M. (1980). Gene regulation at the right operator $\left(\mathrm{O}_{\mathrm{R}}\right)$ of bacteriophage $\lambda$ II. $\mathrm{O}_{\mathrm{R}} 1, \mathrm{O}_{\mathrm{R}} 2, \mathrm{O}_{\mathrm{R}} 3$ : their roles in mediating the effects of repressor and cro. $\mathrm{J}$. Mol. Biol. 139, 163-194.

Michael, B., Smith, J.N., Swift, S., Heffron, F., Ahmer, B.M.M. (2001). SdiA of Salmonella enterica is a LuxR homolog that detects mixed microbial communities. J. Bacteriol. 183, 57335742. 
Miller, M.B., and Bassler, B.L. (2001). Quorum sensing in bacteria. Annu. Rev. Microbiol. 55, 165-199.

Mimee, M., Tucker, A.C., Voigt, C.A., Lu, T.K. (2016). Programming a human commensal bacterium, bacteroides thetaiotaomicron, to sense and respond to stimuli in the murine gut microbiota. Cell. Syst. 1, 62-71.

Myhrvold, C., Kotula, J.W., Hicks, W.M., Conay, N.J., Silver, P.A. (2015). A distributed cell division counter reveals growt dynamics in the gut microbiota. Nat. Comm. 6, 10039.

Passador, L., Cook, J.M., Gambello, M.J., Rust, L., Iglewski, B.H. (1993). Expression of Pseudomonas aeruginosa virulence genes requires cell-to-cell communication. Science 260, 1127-1130.

Peterson, J., Garges, S., Giovanni, M., Mclnnes, P., wang, L., Schloss, J.A., Bonazzi, V., McEwen, J.W., Wetterstand, K.A., Deal, C., Baker, C.C., Di Francesco, V., Howcroft, T.K., Karp, R.W., Lunsford, R.D., Wellington, C.R., Belachew, T., Wright, M., Giblin, C., David, H., Mills, M., Salomon, R., Mullins, C., Akolkar, B., Begg, L., Davis, C., Grandison, L., Humble, M., Khalsa, J., Roger Little, A., Peavy, H., Pontzer, C., Portnoy, M., Sayre, M.H., Starke-Reed, P., Zakhari, S., Read, J., Watson, B., Guyer, M. (2009). The NIH Human Microbiome Project Genome Res. 19, 2317-2323.

Piper, K.R., Beck von Bodman, S., Farrand, S.K. (1993). Conjugation factor of Agrobacterium tumefaciens regulates Ti plasmid transfer by autoinduction. Nature 362, 448-450.

Ptashne, M. (1986). A genetic switch: Gene control and phage. lambda. United States: N. p., Web.

Ptashne, M., and Gann, A. (2002). Genes \& Signals. United States: Cold Spring Harbor Laboratory Press.

Rakoff-Nahoum, S., Coyne, M.J., Comstock, L.E. (2014). An ecological network of polysaccharide utilization among human intestinal symbionts. Curr. Biol. 24, 40-49.

Ridaura, V.K., Faith, J.J., Rey, F.E., Cheng, J., Duncan, A.E., Kau, A.L., Griffin, N.W., Lombard, V., Henrissat, B., Bain, J.R., Muehlbauer, M.J., Ilkayeva, O., Semenkovich, C.F., Funai, K., Hayashi, D.K., Lyle, B.J., Martini, M.C., Ursell, L.K., Clemente, J.C., Van Treuren, W., Walters, W.A., Knight, R., Newgard, C.B., Heath, A.C., Gordon, J.I. (2013). Gut microbiota from twins discordant for obesity modulate metabolism in mice. Science 341, 1241214.

Riglar, D.T., and Silver, P.A. (2018). Engineering bacteria for diagnostic and therapeutic applications. Nat. Rev. Microbiol. 16, 214-225.

Riglar, D.T., Giessen, T.W., Baym, M., Kerns, S.J., Niederhuber, M.J., Bronson, R.T., Kotula, J.W., Gerber, G.K., Way, J.C., Silver, P.A. (2017). Engineered bacteria can function in the mammalian gut long-term as live diagnostics of inflammation. Nat. Biotechnol. 35, 653-658. 
Rosemeyer, V., Michiels, J., Verreth, C., Vanderleyden, J. (1998). luxI- and luxR-homologous genes of Rhizobium etli CNPAF512 contribute to synthesis of autoinducer molecules and nodulation of Phaseolus vulgaris. J. Bacteriol. 180, 815-821.

Sampson, T.R., Debelius, J.W., Thron, T., Janssen, S., Shastri, G.G., Ilhan, Z.E., Challis, C., Schretter, C.E., Rocha, S., Gradinaru, V., Chesselet, M-F., Keshavarzian, A., Shannon, K.M., Krajmalnik-Brown, R., Wittung-Stafshede, P., Knight, R., Mazmanian, S.K. (2016). Gut microbiota regulate motor deficits and neuroinflammation in a model of Parkinson's disease. Cell 167, 1469-1480.

Scott, S.P., Din, M.O., Bittihn, P., Xiong, L., Tsimring, L.S., Hasty, J. (2017). A stabilized microbial ecosystem of self-limiting bacteria using synthetic quorum-regulated lysis. Nat. Microbiol. 2, 17083.

Slauch, J.M., and Camilli, A. (2000). IVET and RIVET: Use of gene fusions to identify bacterial virulence factors specifically induced in host tissues. Methods Enzymol. 326, 73-96.

Sleight, S.C. and Sauro, H.M. (2013). Visualization of evolutionary stability dynamics and competitive fitness of Escherichia coli engineered with randomized multigene circuits. ACS Synth. Biol. 2, 519-528.

Smillie, C.S., Sauk, J., Gevers, D., Friedman, J., Sung, J., Youngster, I., Hohmann, E.L., Staley, C., Khoruts, A., Sadowsky, M.J., Allegretti, J.R., Smith, M.B., Xavier, R.J., Alm, E.J. (2018). Strain tracking reveals the determinants of bacterial engraftment in the human gut following fecal microbiota transplantation. Cell Host Microbe 23, 229-240.

Steindler, L., Venturi, V. (2007). Detection of quorum-sensing N-acyl homoserine lactone signal molecules by bacterial biosensors. FEMS Microbiol. Lett. 266, 1-9.

Stirling, F., Bitzan, L., O'Keefe, S., Redfield, E., Oliver, J.W.K., Way, J., and Silver, P.A. (2017). Rational design of evolutionarily stable microbial kill switches. Mol. Cell 68, 686-697.

Swearingen, M.C., Sabag-Daigle, A., Ahmer, B.M.M. (2013). Are there acyl-homoserine lactones within mammalian intestine? J. Bacteriol. 195, 173-179.

Swift, S., Downie, J.A., Whitehead, N.A., Barnard, A.M., Salmond, G.P., and Williams, P. (2001). Quorum sensing as a population-density-dependent determinant of bacterial physiology. Adv. Microb. Physiol. 45, 199-270.

Tabor, J.J., Salis, H.M., Simpson, Z.B., Chevalier, A.A., Levskaya, A., Marcotte, E.M., Voigt, C.A., Ellington, A.D. (2009). A synthetic genetic edge detection program. Cell 137, 1272-1281.

Tamsir, A., Tabor, J.J., Voigt, C.A. (2011). Robust multicellular computing using genetically encoded NOR gates and chemical 'wires'. Nature 469, 212-215. 
Thaiss, C.A., Zeevi, D., Levy, M., Zilberman-Schapira, G., Suez, J., Tengeler, A.C, Abramson, L., Katz, M.N., Korem, T., Zmora, N., Kuperman, Y., Biton, I., Gilad, S., Harmelin, A., Shapiro, H., Halpern, Z., Segal, E., Elinav, E.. (2014). Transkingdom control of microbiota diurnal oscillations promotes metabolic homeostasis. Cell 159, 514-529.

Thomas, C.M. and Versalovic, J. (2010). Probiotics-host communication: Modulation of signaling pathways in the intestine. Gut Microbes 1, 148-163.

Thompson, J.A., Oliveira, R.A., Djukovic, A., Ubeda, C., Xavier, K.B. (2015). Manipulation of the quorum sensing signal AI-2 affects the antibiotic-treated gut microbiota. Cell Reports 10, 1861-1871.

Turnbaugh, P.J., Ridaura, V.K., Faith, J.J., Rey, F.E., Knight, R., Gordon, J.I. (2009). The effect of diet on the human gut microbiome: a metagenomic analysis in humanized gnotobiotic mice. Sci. Transl. Med. 1, 6ra14.

Walker, A., Pfitzner, B., Neschen, S., Kahle, M., Harir, M., Lucio, M., Moritz, F., Tziotis, D., Witting, M., Rothballer, M., Engel, M., Schmid, M., Endesfelder, D., Klingensopor, M., Rattei, T., zu Castell, W., Hrabé de Angelis, M., Hartmann, A., Schimitt-Kopplin, P. (2014). Distinct signatures of host-microbial meta-metabolome and gut microbiome in two C57BL/6 strains under high-fat diet. ISME J 8, 2380-2396.

Whitaker, W.R., Shepherd, E.S., Sonnenburg, J.S. (2017). Tunable expression tools enable single-cell strain distinction in the gut microbiome. Cell 169, 538-546.

Wu, G., Yan, Q., Jones, J.A., Tang, Y.J., Fong, S.S., Koffas, M.A.G. (2016). Metaboilc burden: cornerstones in synthetic biology and metabolic engineering applications. Trends. Biotechnol. 34, 652-664.

Xiong, W., Abraham, P.E., Li, Z., Pan, C., Hettich, R.L. (2015). Microbial metaproteomics for characterizing the range of metabolic functions and activities of human gut microbiota. Proteomics 15, 3424-3438.

Yano, J.M., Yu, K., Donaldson, G.P., Shastri, G.G., Ann, P., Ma, L., Nagler, C.R., Ismagilov, R.F., Mazmanian, S.K., Hsiao, E.Y. (2015). Indigenous bacteria from the gut microbiota regulate host serotonin biosynthesis. Cell 161, 264-276.

Zhernakova, A., Kurilshikov, A., Bonder, M.J., Tigchelaar, E.F., Schirmer, M., Vatanen, T., Mujagic, Z., Vila, A.V., Falony, G., Vieira-Silva, S., Wang, J., Imhann, F., Brandsma, E., Jankipersadsing, S.A., Joossens, M., cenit, M.C., Deelen, P., Swertz, M.A., Lifelines Cohort study, Weersma, R.K., Feskens, E.J., Netea, M.G., Gevers, D., Jonkers, D., Franke, L., Aulchenko, Y.S., Huttenhower, C., Raes, J., Jofker, M.H., Xavier, R.J., Wijmenga, C., Fu, J. (2016). Population-based metagenomics analysis reeals markers for gut microbiome composition and diversity. Science 352, 565-569. 
Zhu, J., Chai, Y., Zhong, Z., Li, S., Winans, S.C. (2003). Agrobacterium bioassay strain for ultrasensitive detection of $\mathrm{N}$-acylhomoserine lactone-type quorum-sensing molecules: detection of autoinducers in Mesorhizobium huakuii. Appl. Environ. Microbiol. 69, 6949-6953.

Zou, J., Chassaing, B., Singh, V., Pellizzon, M., Ricci, M., Fythe, M.D., Kumar, M.V., Gewirtz, A.T. (2018). Fiber-mediated nourishment of gut microbiota protects against diet-induced obesity by restoring IL-22-mediated colonic health. Cell Host Microbe 23, 41-53.

Zucca, S., Pasotti, L., Mazzini, G., De Angelis, M.G.C., Magni, P. (2012). Characterization of an inducible promoter in different DNA copy number conditions. BME Bioinformatics 13, S11. 